\title{
Perspectives on menopause and women with HIV
}

This article was published in the following Dove Press journal:

International Journal of Women's Health

II January 2016

Number of times this article has been viewed

\author{
Nisha Andany' \\ $\checkmark$ Logan Kennedy ${ }^{2}$ \\ Muna Aden ${ }^{2}$ \\ Mona Loutfy ${ }^{1,2}$
}

'Department of Medicine, University of Toronto, Toronto, ON, Canada;

${ }^{2}$ Women's College Research Institute,

Women's College Hospital, Toronto,

ON, Canada
Correspondence: Mona Loutfy Women's College Research Institute, Women's College Hospital, 76 Grenville Street, 6th Floor, Toronto, ON M5S IB2, Canada Tel + I 4167259566

Email mona.loutfy@wchospital.ca
Abstract: Since the implementation of effective combination antiretroviral therapy, HIV infection has been transformed from a life-threatening condition into a chronic disease. As people with HIV are living longer, aging and its associated manifestations have become key priorities as part of HIV care. For women with HIV, menopause is an important part of aging to consider. Women currently represent more than one half of HIV-positive individuals worldwide. Given the vast proportion of women living with HIV who are, and will be, transitioning through agerelated life events, the interaction between HIV infection and menopause must be addressed by clinicians and researchers. Menopause is a major clinical event that is universally experienced by women, but affects each individual woman uniquely. This transitional time in women's lives has various clinical implications including physical and psychological symptoms, and accelerated development and progression of other age-related comorbidities, particularly cardiovascular disease, neurocognitive dysfunction, and bone mineral disease; all of which are potentially heightened by HIV or its treatment. Furthermore, within the context of HIV, there are the additional considerations of HIV acquisition and transmission risk, progression of infection, changes in antiretroviral pharmacokinetics, response, and toxicities. These menopausal manifestations and complications must be managed concurrently with HIV, while keeping in mind the potential influence of menopause on the prognosis of HIV infection itself. This results in additional complexity for clinicians caring for women living with HIV, and highlights the shifting paradigm in HIV care that must accompany this aging and evolving population.

Keywords: HIV, women, aging, menopause

\section{Introduction}

The nature of the human immunodeficiency virus (HIV) pandemic has changed dramatically since discovered over 33 years ago. Extraordinary progress has been achieved in the management of HIV with the advent of combination antiretroviral therapy (cART), which can effectively control viral replication, and has resulted in remarkable reductions in HIV-associated morbidity and mortality. ${ }^{1-4}$ In today's landscape, the reported life expectancy for a person newly diagnosed with HIV, in the context of access to cART, can approach that of the general population. ${ }^{5}$ One of the greatest medical victories of this generation has been the transformation of HIV from an acute, life-limiting infection to a chronic disease with incredibly effective treatment. ${ }^{2}$

In addition to the marked changes in morbidity and life expectancy, the evolving epidemiology of HIV infection has seen an escalating impact on women. Current data suggest that of the 35 million people living with HIV worldwide, 52\% are women. The proportion of infected women varies geographically: ${ }^{6}$ in Sub-Saharan Africa, women represent approximately $57 \%$ of those with HIV, ${ }^{6}$ while in developed countries such as Canada and the USA, this proportion is markedly lower at $22 \%$ to $23 \%$. $^{7,8}$ The vulnerability that women experience related to HIV, with respect to both the causes and consequences of infection, is a complex phenomenon resulting from biological and sociopolitical inequities. ${ }^{6,7}$ 
In earlier stages of the pandemic, the principal concerns surrounding HIV infection in women centered on sexual and reproductive health, largely due to the high rates of HIV infection among women of reproductive age and the risks of vertical transmission. However, in the current era of increasingly accessible and efficacious cART, and longer life expectancies, HIV in the context of increased age becomes a key clinical consideration. ${ }^{9,10}$ In 2011, 26\% of individuals living with HIV in the USA were greater than 55 years of age. ${ }^{11}$ It is anticipated that by 2020 , up to $70 \%$ of HIV infection will be in patients over the age of 70 years. ${ }^{12}$ Five percent of new infections in the USA are estimated to occur in those greater than 55 years of age, and older Americans are more likely to present in later stages of the disease. ${ }^{11}$ Consequently, issues pertaining to age-related comorbidities and other life events, including menopause, represent an emerging aspect of HIV care. ${ }^{9,13}$

The World Health Organization (WHO) defines natural menopause as the permanent cessation of menses. Specifically, this refers to a period of amenorrhea of at least 12 months that is due to the loss of ovarian follicular activity, and occurs in the absence of any other physiologic or pathologic process. ${ }^{14,15}$ This is in contrast to other forms of menopause, in which an alternative etiology can be identified (Table 1). ${ }^{15}$ Natural menopause typically occurs between the ages of 50 and 52 years in developed nations, but there is considerable geographic variation with respect to age of onset throughout the world. ${ }^{16-20}$ As hormone production in the ovaries declines with age, and eventually ceases entirely, the menopausal transition occurs in three stages (Figure 1). ${ }^{21}$ Menopause is a complex clinical process that is uniquely experienced by each woman, and is associated with various biological and psychosocial changes including alterations in bone health, cognition, risk of other age-related comorbidities, and an array of physical and psychological symptoms. ${ }^{13,22-27}$ Women around the world from various cultural groups, races, and religions have been found to report diverse biological, sociocultural, and psychological factors that influence their experiences and perceptions related to menopause. ${ }^{23,28,29}$ In women living with HIV, an intricate relationship between HIV and menopause appears to exist in that HIV may influence the natural history, experience, and complications of menopause, while menopause itself could potentially influence the course of HIV infection. ${ }^{28}$ This bidirectional relationship between HIV infection and menopause confers an additional layer of complexity to the ongoing management of HIV-infected women as they age, and presents new and vaguely understood challenges for clinicians.

\section{Impact of menopause on HIV infection \\ Aging, menopause, and transmission of HIV}

As individuals age, they continue to represent an important, but often overlooked, population at risk of acquiring HIV and other sexually transmitted infections (STIs). ${ }^{11,30}$ This has implications both from an individual and public health perspective. In 2010, approximately $5 \%$ of new HIV diagnoses in the USA occurred in adults greater than 55 years of age. ${ }^{11}$ Furthermore, older adults diagnosed with HIV tend to be diagnosed later on in the course of their disease, which can affect severity of immune dysfunction, response to treatment, and survival..$^{11,31-34}$ In the USA in 2013, 27\% of AIDS diagnoses, the most advanced stage of HIV infection, ${ }^{35}$ occurred in patients greater than 50 years of age. ${ }^{11}$ Additionally, while $98 \%$ of patients diagnosed with HIV between the ages of 20-29 years in the USA will survive beyond 12 months, the prognosis for new diagnoses in older adults is substantially lower. The proportion of those who survive for more than 1 year after diagnosis declines with increasing age, from $86 \%$ among those diagnosed at ages $50-59$ years, to $82 \%$ among those aged $60-64$ years, and $73 \%$ in those diagnosed at age 65 years and older. ${ }^{11}$

The primary mode of HIV transmission and acquisition in people over the age of 50 years is through sexual contact. ${ }^{11}$ While sexual activity does decline with age, many

Table I Classification of menopausal states ${ }^{14,15,22}$

\begin{tabular}{|c|c|}
\hline Term & Definition \\
\hline Natural menopause & $\begin{array}{l}\text { Permanent cessation of menstruation resulting from a loss of ovarian follicular activity; diagnosis is made } \\
\text { retrospectively after } 12 \text { months of amenorrhea in the absence of any other pathological or physiological cause }\end{array}$ \\
\hline Perimenopause & $\begin{array}{l}\text { The period immediately prior to menopause, when the endocrinological, biological, and clinical features of } \\
\text { approaching menopause commence, and the first year after menopause }\end{array}$ \\
\hline $\begin{array}{l}\text { Premature menopause } \\
\text { (or premature ovarian failure) }\end{array}$ & $\begin{array}{l}\text { Menopause that occurs at an age less than two standard deviations below the mean established for the reference } \\
\text { population; generally, refers to menopause prior to the age of } 40 \text { years }\end{array}$ \\
\hline Induced menopause & $\begin{array}{l}\text { Cessation of menstruation that follows either surgical removal of both ovaries (with or without hysterectomy) } \\
\text { or iatrogenic ablation of ovarian function (including chemotherapy or radiation therapy) }\end{array}$ \\
\hline
\end{tabular}




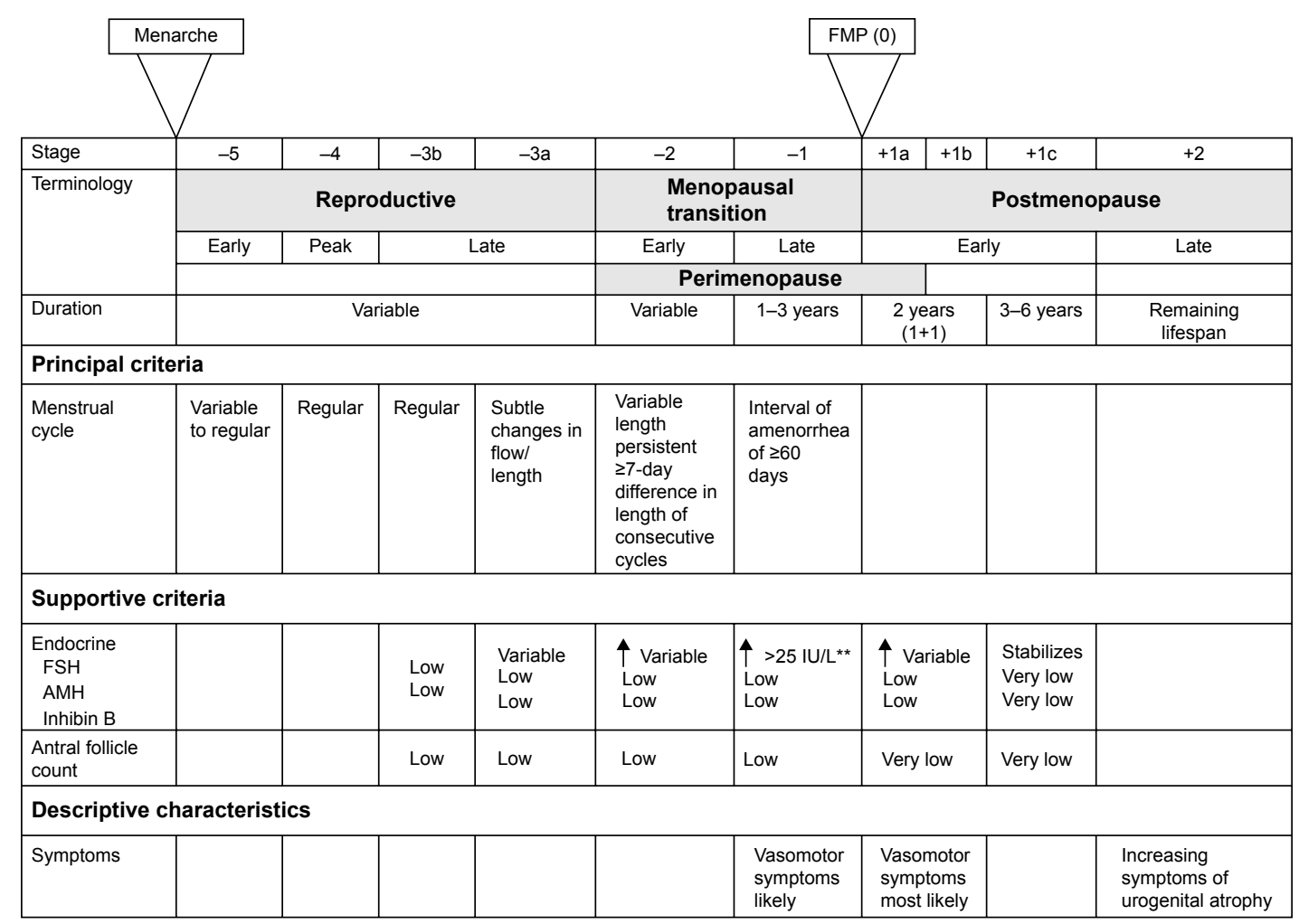

Figure I The stages of the menopausal transition in women.

Notes: **Approximate expected level based on assays using current international pituitary standard. From Harlow SD, Gass M, Hall JE, et al. Executive summary of the stages of reproductive aging workshop +10: addressing the unfinished agenda of staging reproductive aging. Menopause. 2012;19(4):387-395. ${ }^{21}$ With permission from Wolters Kluwer Health, Inc. Copyright @20I2.

Abbreviations: $\mathrm{FSH}$, follicle-stimulating hormone; FMP, final menstrual period; $\mathrm{AMH}$, anti-Mullerian hormone.

older individuals will continue to remain sexually active after the age of 50 years. ${ }^{11,30,36-38} \mathrm{In}$ an assessment of sexual behavior in adults in the USA, 59\% of women aged 55-59 years had engaged in sexual activity in the past year. ${ }^{30,39}$ A similar study of adults over the age of 60 years in the USA found that $71 \%$ of men and $51 \%$ of women remained sexually active. ${ }^{30,40}$ Furthermore, $30 \%$ of women in their 70 s and $20 \%$ of those in their 80 s engaged in some measure of sexual activity. ${ }^{30,40}$ Older adults will report sexual activity regardless of marital status, and may continue to engage in diverse sexual activities including vaginal-penile intercourse, oral sex, and receptive and insertive anal intercourse. ${ }^{30,39-42}$ These individuals, therefore, retain traditional risk factors for HIV acquisition. Condom use is an effective measure to prevent sexual transmission of HIV. However, with reduced fertility in the later years, condom use has been found to decline. ${ }^{43-46}$ The lack of condom use in older adults may be further explained by the misperception that they are at minimal risk of contracting HIV and other STIs. ${ }^{37,47}$ In fact, in an analysis of responses from 12,366 adults aged 50 years and older in the 2009 National Health Interview Survey in the USA, $84.1 \%$ believed they had zero chance of becoming infected with HIV. ${ }^{47}$ This underestimation of HIV-acquisition risk in older patients also extends to their physicians. ${ }^{11,37,48-50}$ For example, one study demonstrated that among individuals aged 58-93 years, of whom $57 \%$ were sexually active after the age of 60 years, $11 \%$ had received STI/HIV counselling from their physicians, and only $4 \%$ had ever been offered an HIV test. ${ }^{37}$ For postmenopausal women specifically, physiologic changes such as vaginal dryness, vaginal atrophy, and decreased libido likely contribute to reduced sexual activity. However, these changes in vaginal tissue may also increase biologic predisposition to acquiring HIV infection, even with reduced sexual contact. ${ }^{6,9,11,51,52}$ Therefore, it is important that physicians and other health care providers continue to discuss sexual behaviors with their aging patients, and counsel them on strategies to prevent HIV and other STIs. It is equally critical that HIV testing be offered to older adults who remain sexually active.

Continuation of sexual activity into older age has also been demonstrated in the HIV-positive population. ${ }^{32,36,53}$ In an assessment of women aged 40-57 years in the Women's Interagency Health Study (WIHS), a prospective cohort study of HIV-positive and -negative women in the USA, 73\%-74\% 
of HIV-positive women remained sexually active. ${ }^{36}$ This included women with detectable and undetectable viral loads. ${ }^{36}$ With increasing age, there were similar patterns of reduced sexual activity between sero-positive and seronegative women in the cohort. ${ }^{36}$ Similarly, a study of 123 HIV-positive women over the age of 50 years in the UK found that $60 \%$ remained sexually active. ${ }^{32}$ Unfortunately, up to one-third of older, HIV-infected patients report having unprotected intercourse, including with serodiscordant partners. ${ }^{36,53}$ While limited reproductive potential and underestimation of STI acquisition risk have been postulated as the reasons for low condom use in older adults, additional factors among people with HIV, including fear of HIV-related stigma and forced disclosure of HIV status, may also contribute to suboptimal condom use. ${ }^{11,43,44,54-56}$ Studies exploring condom use among postmenopausal women with HIV have suggested that approximately $70 \%$ use condoms..$^{54,55,57}$ In the WIHS, menopausal status itself was not found to impact condom use in HIV-positive women; however, overall condom use was reported in only $74 \%$ of premenopausal and $70 \%$ of postmenopausal women. ${ }^{54}$ When adjustments for sero-status were performed in a multivariable model, no significant difference in condom use was found between the HIV-positive and HIV-negative women. ${ }^{54}$

In addition to the aforementioned need for improved condom use in older adults, prevention strategies specific to HIV-positive individuals also include "treatment as prevention". This strategy is garnering increased attention in light of the evidence showing that there is minimal risk of HIV transmission from people on cART with fully suppressed viral loads. ${ }^{58,59}$ Treatment as prevention can be an important HIV prevention strategy among older adults. However, clinicians should promote safer sex practices in all of their adult patients for the prevention of other STIs.

Studies have also attempted to determine if menopausal status affects cervical shedding of the HIV virus, thereby increasing the risk of sexual transmission. However, these results have been inconsistent. An in vitro study of ectocervical tissues from pre- ( $<45$ years) and postmenopausal ( $>55$ years of age) women, in which tissue samples were ex vivo infected with HIV-1 virus after hysterectomy, found higher levels of viral transcription in postmenopausal vs premenopausal samples. ${ }^{60}$ This could potentially have clinical implications if recently infected postmenopausal women, in the setting of already reduced condom use, are more likely to transmit the virus to others because of higher cervical viral shedding. However, this finding has not been replicated in any in vivo studies. Melo et al ${ }^{61}$ performed a cross-sectional study of pre- and postmenopausal, HIV-positive women in Brazil. They found no association between menopausal status and in vivo cervico-vaginal viral shedding; rather, degree of shedding was, as expected, associated with plasma viral load and vaginal $\mathrm{pH} .{ }^{61}$ Once again, this emphasizes the importance of antiretroviral treatment and virologic suppression in the HIV prevention armamentarium.

\section{Menopause and progression of HIV}

As women with HIV transition through menopause, the progression of their infection and response to treatment in the setting of altered reproductive hormones is a key consideration. Older patients with HIV who are not on cART have lower baseline CD4 counts than younger patients. ${ }^{31}$ A component of this is likely related to age, as lymphocyte subsets, including CD4 counts, have been found to decrease with increasing age in non-HIV-infected adults. ${ }^{62}$ In those with HIV, timing of diagnosis is also a potential contributor. Older individuals are less likely to be tested for HIV and are more likely to be diagnosed with HIV later on in the course of the disease. ${ }^{11,31}$ This can result in lower CD4 set points at the time of antiretroviral initiation and a blunted response to treatment. ${ }^{11,28,31,63-65}$ However, menopausal status itself may also contribute to lower CD4 counts. ${ }^{28}$ With age and menopause, quantity of thymic tissue is reduced, which has implications for immunologic status. ${ }^{28}$ In a study of 382 HIV-positive women not on cART, with a known period of sero-conversion, a regression analysis modeling CD4 decline found a trend for postmenopausal women having lower CD4 counts 3 years after sero-conversion compared to premenopausal women (333 cells $/ \mu \mathrm{L}$ vs 399 cells $/ \mu \mathrm{L}$, $P=0.09) .{ }^{66}$ However, this result did not achieve statistical significance and furthermore, there was no difference in the rate of $\mathrm{CD} 4$ decline. ${ }^{66}$

More recent studies have generally yielded promising results, finding that menopausal status itself does not influence response to antiretroviral treatment. ${ }^{67,68}$ In 267 treatment-naïve women living with HIV, 47 of whom were postmenopausal, CD4 and viral load response to antiretroviral initiation did not differ between those who were pre- and postmenopausal. ${ }^{67}$ Postmenopausal women were able to maintain viral suppression through a 96-week follow-up period. ${ }^{67}$ Similarly, in a prospective cohort study of 383 antiretroviral-naïve, HIV-infected women in Brazil (85\% premenopausal and $15 \%$ postmenopausal), menopausal status had no effect on treatment response at 24 months post-initiation of therapy ${ }^{68}$ Pre- and postmenopausal women, with similar baseline CD4 counts $\left(231\right.$ cells $/ \mathrm{mm}^{3}$ compared 
to 208 cells $/ \mathrm{mm}^{3}, P=0.14$ ), were equally likely to achieve virologic suppression. Interestingly, postmenopausal women had a lower median CD4 response than premenopausal women at the 24-month postantiretroviral therapy (ART) time point ( 184 cells $/ \mathrm{mm}^{3}$ vs 273 cells $/ \mathrm{mm}^{3}, P=0.02$ ); however, when this analysis was restricted to the women who achieved a viral load $<400$ copies/mL, there was no longer a difference in CD4 response $(P=0.27) .{ }^{68}$

With increased age and menopause, alterations in drug pharmacokinetics may result from changes in volume of distribution and renal and hepatic clearance, which may further have implications for treatment responses and toxicities in elderly patients. ${ }^{69}$ Gervasoni et al attempted to determine if antiretroviral levels were affected by menopause. They found that between 28 pre- and 22 postmenopausal women, there was no difference in plasma levels of tenofovir (TDF), a commonly used nucleotide reverse transcriptase inhibitor (NRTI). ${ }^{70}$ Similarly, Cottrell et al found no difference in steady-state area under the curve plasma levels of the integrase inhibitor, raltegravir, between HIV-positive pre- vs postmenopausal women. ${ }^{71}$ Nevertheless, increased plasma drug concentrations are known to occur in elderly patients, ${ }^{72}$ and clearly need to be considered in the management of menopausal HIV-positive women as they could be at higher risk of drug toxicities than their younger, premenopausal counterparts. ${ }^{73}$ However, an independent effect of menopausal status on antiretroviral pharmacokinetics has not been established.

\section{Impact of HIV infection on menopause Age of menopause}

Natural menopause typically occurs between the ages of 50 and 52 years. ${ }^{16,17}$ However, average age of menopause displays significant country-to-country variation and therefore, an examination of the age of onset of menopause in any subpopulation requires comparison to the national average. ${ }^{18,20}$ Most studies operationalize the term "early menopause" as menopause occurring between the ages of 40 and 45 years, ${ }^{13-15,19,22,74}$ and premature menopause (sometimes referred to as premature ovarian failure) as menopause occurring before the age of 40 years (Table 1). 14,15,22 Early and premature menopause have important clinical implications. They are linked to alterations in mood and sexual function, declines in quality of life, development of comorbidities such as cardiovascular disease, osteoporosis, and fragility fractures, and have been associated with earlier mortality. ${ }^{22,75-79}$ Therefore, an understanding of which populations are at increased risk of early and premature menopause is important for the counseling and management of female patients, as well as for the assessment of hormone therapy (HT) initiation if clinically indicated. ${ }^{9}$

Within the HIV-positive community, several reports have demonstrated that the average age of menopause is lower than the general population, and that women with HIV are at higher risk of developing early and premature menopause (Table 2). ${ }^{13,19,32,80-84}$ In a study of 268 women living with HIV in Thailand, the average age of menopause was 2.2 years earlier than the national average. ${ }^{82}$ In this study, the earlier age of menopause occurred independent of immunologic (CD4 count and viral load) and socio-demographic variables (age of menarche, marital status, parity, education, or income). Calvet et $\mathrm{al}^{19}$ assessed $667 \mathrm{HIV}$-positive women in Brazil, and found that median age of menopause was 48 years (interquartile range: $45-50$ years), which is lower than the average age of menopause in the general population. Additionally, $27 \%$ of women in this study experienced menopause before 45 years of age. ${ }^{19}$ In the USA, age of menopause onset in women living with HIV has ranged from 46 to 50 years across various studies. ${ }^{13,80,81,83,84}$ Fantry et al demonstrated that in $120 \mathrm{HIV}$-positive women, 35\% reported early menopause, ${ }^{13}$ while Schoenbaum et al found that $26 \%$ of HIV-positive women in New York experienced premature menopause, significantly higher than the $10 \%$ reported in the HIV-negative counterparts. ${ }^{81}$ Conversely, other studies have failed to demonstrate an earlier age of menopause when comparing HIV-positive and HIV-negative women. ${ }^{74,83,85}$ In a prospective cohort study of women living with HIV in France, the median age of onset of menopause was 49 years (interquartile range: 40-50 years), which was comparable to the general population in France. ${ }^{74,86}$ However, it is important to note that in this study, $22 \%$ of women reported early menopause and $12 \%$ experienced premature menopause. ${ }^{74}$ Cejtin et al performed a study of 1,335 women in the WIHS, and found no difference in the mean age of menopause between sero-positive (47.7 years) and sero-negative women (48 years). ${ }^{83,87}$ However, in a follow-up study of 1,431 women in the same cohort, the median age of menopause onset in the entire sample was 47 years, which is lower than the national average in the USA. ${ }^{85}$ This raises the possibility that the entire patient population was at risk of early menopause, thereby impairing the ability to demonstrate a difference between those with and without HIV infection. Alternatively, this study has been the only one to examine the age of menopause with a biochemical confirmation of ovarian failure, which may result in a more accurate assessment of menopause than self-report. Fantry et al also failed to show an earlier age of menopause in HIV-positive women in Baltimore. ${ }^{13}$ 


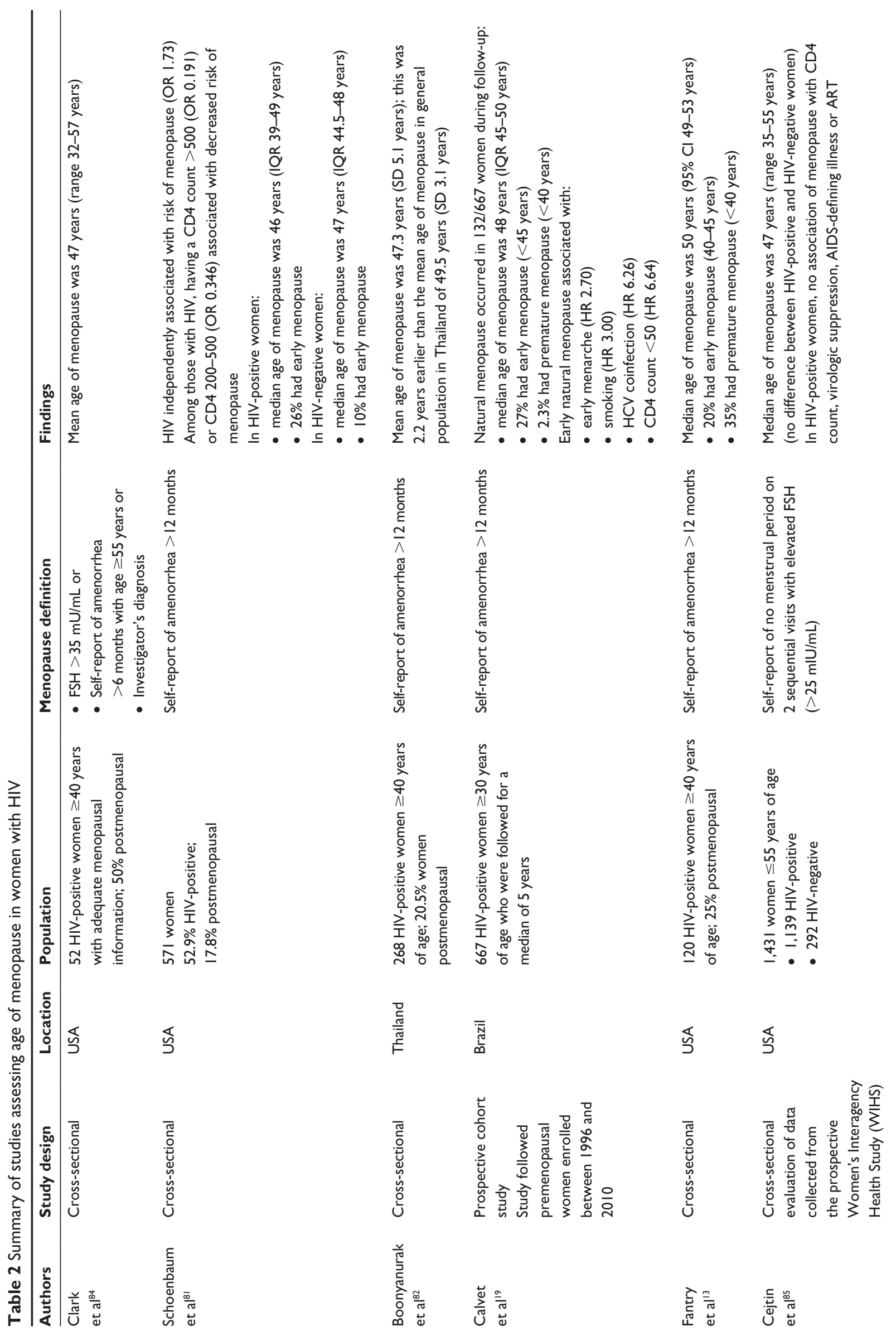




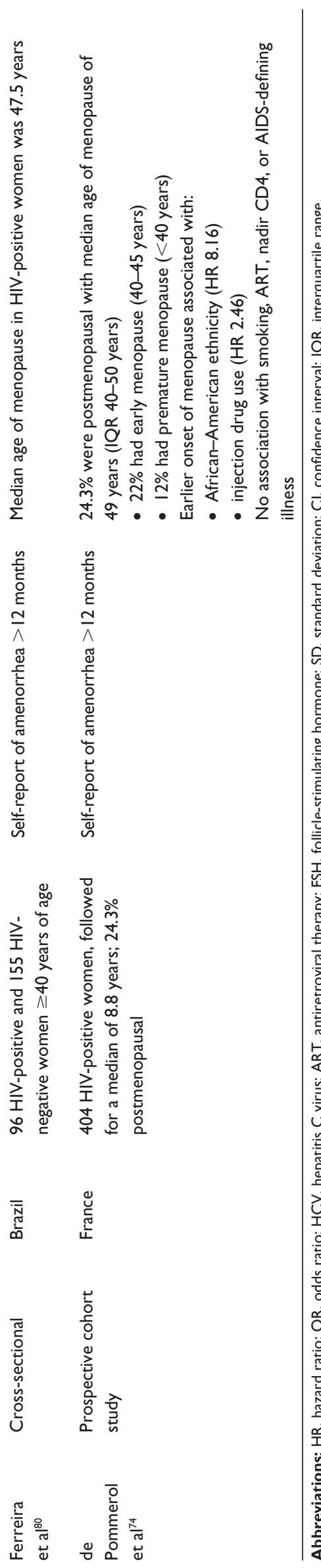

In this study, median age of menopause was 50 years $(95 \%$ confidence interval 49-53); however, 55\% of menopausal women reported early menopause ( $<45$ years), and $35 \%$ reported premature ovarian failure ( $<40$ years), which is substantially higher than the $5 \%$ and $1 \%$ of early menopause and premature ovarian failure reported in the general population, respectively. ${ }^{13,22}$ Unfortunately, this study did not enroll an HIV-negative control group for comparison, and the small sample size limits the interpretation of these proportions.

The association between HIV-positivity and early menopause is likely multifactorial and subject to confounding by other factors, which contributes to variation in patient populations, and limits the ability to compare studies. It has been consistently shown that several risk factors for early menopause, including African-American ethnicity, ${ }^{74,81,85,88-90}$ smoking, ${ }^{19,81,84}$ and substance use, ${ }^{74,81}$ are more prevalent in HIV-positive patients and can affect the age of menopause. ${ }^{28}$ Additionally, the assessment of age of menopause is complicated by the subjective nature of the diagnosis. The WHO defines menopause based on a self-report of cessation of menstruation, but does not require an evaluation of any biochemical parameters, such as reproductive hormone levels. ${ }^{14,15}$ While this may be appropriate for the general population, it is potentially problematic in women living with HIV. In this population, the higher risk of menstrual irregularity, anovulation, and amenorrhea confounds the ability to accurately assess onset of menopause. ${ }^{18,85,91-93}$ Cejtin et al demonstrated this phenomenon in the aforementioned WIHS study. In this cohort, being HIV-positive was associated with a nearly twofold increased risk of having a period of amenorrhea lasting $\geq 12$ months. ${ }^{85}$ Furthermore, of the 136 women with more than 1 year of amenorrhea, less than half $(46.7 \%)$ had biochemical evidence of menopause with an elevated follicle-stimulating hormone, compared to $68.8 \%$ in the HIV-negative group. This indicated an independently higher risk for women with HIV to have amenorrhea in the absence of menopause, with an odds ratio of 3.16. ${ }^{85}$ Amenorrhea without menopause was more common in those with lower albumin, history of AIDS-defining illness, reduced income, and non-Hispanic ethnicity, highlighting a potential contribution of more severe illness and poorer nutritional status. ${ }^{85}$ Similarly, in a study of stored serum samples from HIV-positive women aged 20-42 years, 48\% demonstrated evidence of anovulation, which was associated with lower CD4 counts. ${ }^{91}$ Therefore, in women with HIV, biochemical confirmation of menopause may be warranted, as this may have implications for contraception counselling, as well as screening for and management of menopause-associated comorbidities. $^{85}$ 
The influence of immunologic status and virologic control on risk and age of menopause among women with HIV has been inconsistent. While some studies have demonstrated a correlation between lower CD4 count and higher risk of early menopause, ${ }^{19,74,81,83}$ other studies have failed to confirm this relationship. ${ }^{13,85}$

\section{Symptoms of menopause}

The exact role and impact of HIV infection on the experience of menopause is far from certain. Women living with HIV may report a different experience of and attitude toward menopause. Menopausal symptoms are contextually dependent, subject to influence by an array of biological, psychosocial and cultural factors, and are uniquely experienced by each individual woman. ${ }^{25-29,80,94} \mathrm{HIV}$-positive women may be more likely to experience menopausal symptoms than those without HIV infection; however, a consistent association has not been found. Furthermore, defining the relationship between HIV and menopausal symptoms is complicated by the difficulty in reliably distinguishing between symptomatology due to aging and menopause vs that due to HIV infection itself and the effects of ART. ${ }^{85,95,96}$

There has been some indication that women with HIV may be more likely to experience vasomotor symptoms when transitioning through menopause (Table 3)..$^{80,82,94,97}$ In their study of HIV-positive Thai women, Boonyanurak et al found that postmenopausal status was, not unexpectedly, associated with more vasomotor night sweats and change in sexual desire when compared to premenopausal women with HIV. ${ }^{82}$ However, all women in this study were HIV-positive. Therefore, the study findings indicate that women with HIV still experience the typical symptoms of menopause, but does not allow for a differentiation of symptom experience between those with and without infection. On the other hand, Ferreira et al did find that HIV infection was independently associated with a $65 \%$ higher risk of reporting menopausal symptoms. ${ }^{80}$ Similarly, in 66 women living in the USA, those with HIV reported a greater severity of hot flashes when compared to women without HIV. ${ }^{97}$ However, these findings have not been consistently reported in the literature, and there have been several studies that have not demonstrated a relationship between HIV-positivity and vasomotor symptoms. ${ }^{27,94,98-101}$ Lui-Filho et al found that vasomotor symptoms were associated with menopausal status, as expected, but were no different between sero-positive and sero-negative women in Brazil. ${ }^{27}$ Additionally, a comparison between HIV-positive and HIV-negative women living in New York City found no difference in the prevalence of hot flashes or vaginal dryness

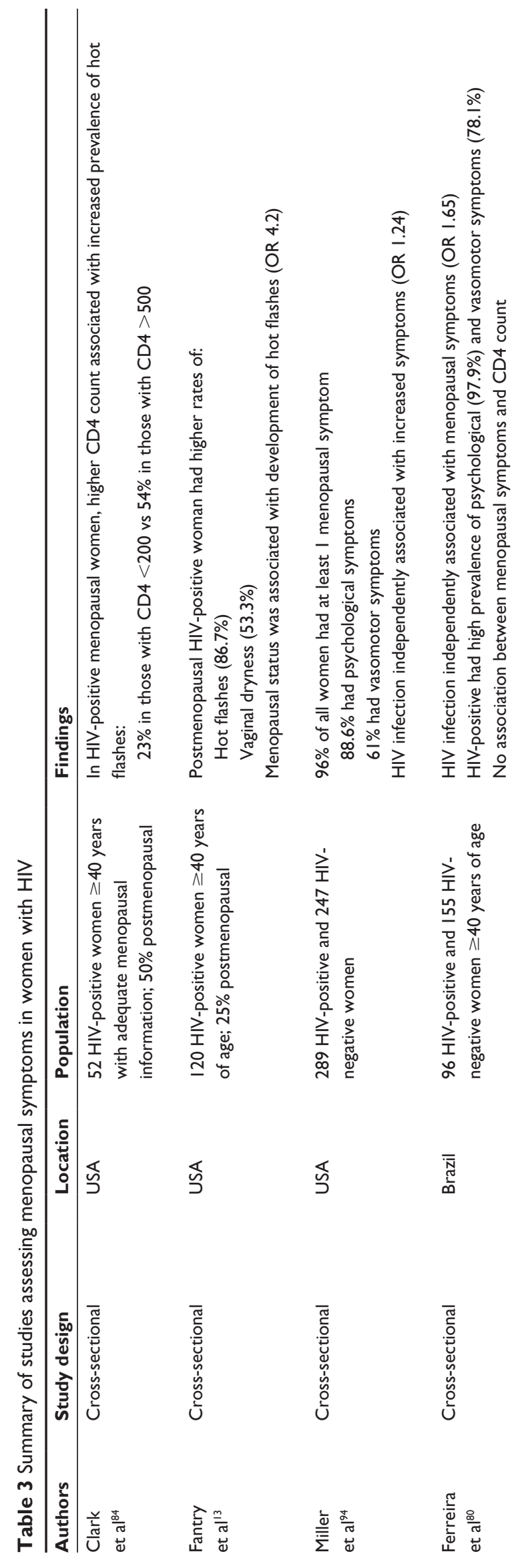




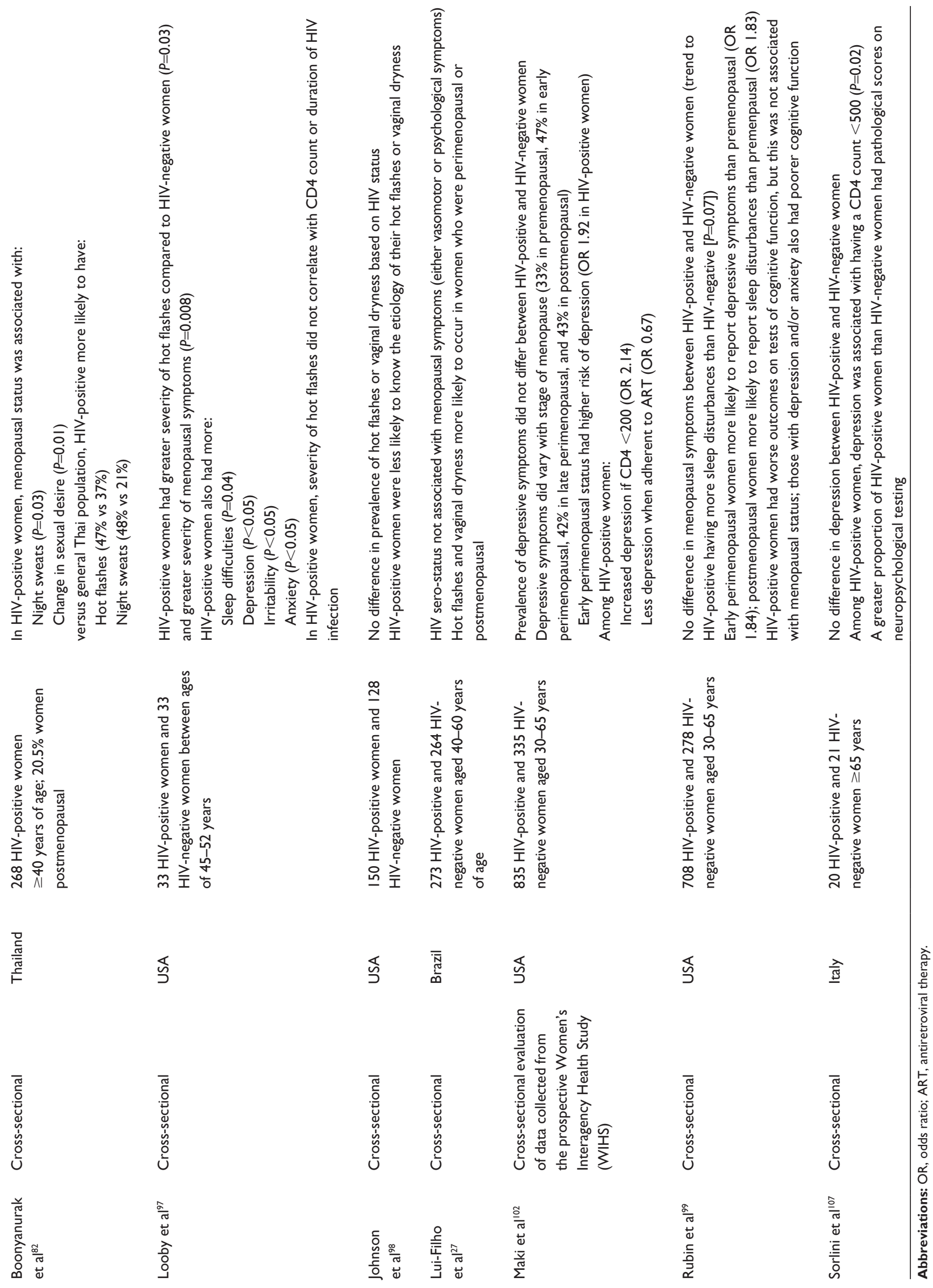


between the two groups. ${ }^{98}$ These contradictory findings also extend to the relationship between immunologic status and experience of symptoms. While one study has found that lower CD4 counts are associated with increased vasomotor symptoms, ${ }^{94}$ others have found no association ${ }^{80,82}$ or even the opposite in that symptoms were more prevalent in women with higher CD4 counts. ${ }^{84}$ Therefore, a clear association has not been established.

Mental health considerations in the postmenopausal period are also of particular importance. However, the relationship between mental health, HIV infection, and other socio-demographic confounders presents a multifaceted and complex picture. The menopausal transition itself, and the accompanying symptoms, regardless of HIV sero-status, can be associated with sleep disturbances, depression, and changes in cognition. ${ }^{94,102}$ Several studies have reported worsened mental health outcomes among women with HIV in the postmenopausal period, including panic attacks, depressive symptoms, and sleep disturbances. ${ }^{80,97,99,102-105}$ However, other studies have failed to replicate this finding. ${ }^{27,82,99,102,106,107}$ Depressive symptoms are also more likely to occur in women who are experiencing menopausal symptoms ${ }^{94,102,108-110}$ and have been associated with reduced quality of life, ${ }^{25,111}$ a negative attitude towards menopause, ${ }^{28,112}$ and decreased adherence to therapy. ${ }^{113,114}$

The impact of menopause and depressive symptoms on cognition is also an important consideration in HIV, as the virus is found in central nervous system tissue and is associated with the HIV-associated neurological disorders. ${ }^{115,116}$ Studies have suggested that compared to men, women with HIV are more likely to have lower education levels and increased difficulty accessing ART, which may result in their being more vulnerable to the development of HIV-associated neurological disorders and dementia. ${ }^{107,116,117}$ In a study of 41 women (20 HIV-positive and $21 \mathrm{HIV}$-negative) in Italy aged 65 years and older, women with HIV had worse performance on tests of executive function, processing speed, and verbal learning than age-matched, HIV-negative controls. ${ }^{107}$ Depression and anxiety can exacerbate these cognitive changes. ${ }^{99,115,116}$ In a study of 708 HIV-positive and 278 HIV-negative women living in the USA, women with HIV had a poorer performance on tests of verbal learning than those without HIV. While this study did not find an independent association between menopausal status and cognitive performance, verbal learning was negatively influenced by symptoms of anxiety, and was likely also influenced by poorer socioeconomic status. ${ }^{99}$ Therefore, if women with HIV are truly more likely to experience depression and anxiety, either independently or due to the menopausal transition and its myriad of symptoms and complications, cognitive function may also be affected.

These differential and contradictory findings with respect to HIV and menopausal symptoms may be related to differences in the study populations, which makes a direct comparison between study results difficult. Differences in socioeconomic status and ethnicity have been shown to influence symptoms and attitudes toward menopause and are likely contributing to the variation in findings. ${ }^{80,94,109,118}$ Women of African-American ethnicity have been found to report more symptoms of menopause when compared to Caucasian and Hispanic women. ${ }^{101}$ Additionally, lower education, poverty, and receipt of social assistance are associated with more menopausal symptoms and may be more prevalent in the HIV-positive community. ${ }^{27,80,94,109,118}$ Method of menopausal symptom assessment is also a key consideration. It has been found that women with HIV may be unable to distinguish between symptoms related to menopause vs those related to HIV itself and ART. ${ }^{95,98}$ They are also less likely than HIV-negative women to have knowledge of what to expect when going through the menopausal transition, which could potentially influence their expectations of aging and have a negative impact on mood if they do not understand why certain symptoms are occurring. ${ }^{95,98}$ These findings may be related to the earlier age of menopause in HIV-infection, in which case symptoms might be misattributed to HIV itself because menopause would be unexpected. ${ }^{98}$ Lower education and socioeconomic status in certain study populations may also partially explain these misperceptions. ${ }^{95}$ Therefore, it is important for clinicians to discuss aging and menopause with their HIV-positive patients, so that they can be better prepared for any changes or symptoms they might develop.

Hormone therapy has been shown to have beneficial effects in certain women with menopause, particularly with respect to vasomotor symptoms and bone health. ${ }^{84,119}$ However, practitioners may be reluctant to provide HT to women with HIV for fear of worsening HIV status, or due to concerns regarding toxicity, increased pill burden, and/or drug-drug interactions with ART. ${ }^{84}$ Consequently, rates of HT use in HIV-positive women are typically very low at approximately $10 \%$ or less. ${ }^{13,32,84,120}$ There have been no published studies examining the utility and/or safety of HT in women with HIV, and there is limited data on use of HT in women on cART. Though there may be drug-drug interactions between HT and some protease inhibitors (PIs) and non-nucleoside reverse transcriptase inhibitors (NNRTIs), including fosamprenavir 
(PI) and efavirenz (NNRTI), newer antiretroviral agents likely do not possess the same pharmacologic concerns. ${ }^{9}$ Prolonged HT has been associated with other medical complications such as breast cancer, thromboembolic disease, and cardiovascular disease. Therefore, current HIV primary care guidelines are similar to those for the general population and suggest that HT, if used, should be provided at the lowest effective dose and for a limited time only. ${ }^{121}$ However, HT is likely being underutilized in women with HIV and should be considered for those who might otherwise benefit due to severe menopausal symptoms, as long as there are no contraindications to therapy. ${ }^{32}$

\section{Bone mineral density (BMD)}

The higher prevalence of amenorrhea and earlier age of menopause that accompany HIV infection in women predisposes them to earlier and more severe bone loss when compared to those without HIV. Osteoporosis, a disorder characterized by decreases in bone density and quality and increased susceptibility to fracture, represents a significant global health burden, particularly for postmenopausal women. ${ }^{120,122}$ The WHO operationally defines osteoporosis as having a BMD score of 2.5 or more standard deviations below the mean for young, healthy women (ie, a T-score $\leq 2.5$ ). ${ }^{122-124}$ Osteoporosis affects more than 75 million people in developed countries; globally, it is responsible for more than 8.9 million fractures per year, ${ }^{124}$ and leads to reductions in quality of life, and a higher risk of morbidity and mortality. ${ }^{120,125,126}$ While increased age and postmenopausal status are the two most important factors predisposing to low BMD and osteoporosis, a variety of additional factors, including lifestyle behaviors, chronic medical conditions and medications, also contribute to bone loss. ${ }^{122,127,128} \mathrm{HIV}$ is an important risk factor for impaired bone health. ${ }^{120,122,129-134}$ The prevalence of low BMD among those with HIV ranges from 30\% to $70 \%,{ }^{131,134}$ while up to $15 \%$ of patients with HIV have osteoporosis. ${ }^{135-137}$ However, the development of bone disease in HIV is likely a multifactorial process that includes the effects of HIV infection itself, higher prevalence of other osteoporosis risk factors, as well as the impact of ART. 9,23,120,122,132-134,138-142

Several studies have demonstrated that patients with HIV are more likely to experience additional osteoporosis risk factors including cigarette smoking and alcohol use, AfricanAmerican or Hispanic ethnicity, decreased body mass index, vitamin D deficiency, chronic steroid use, amenorrhea, and hypogonadism..$^{9,23,122,127,128,131,134,143-154}$ However, there is evidence that HIV infection itself, independent of its association with these other factors, contributes to bone loss
(Table 4). ${ }^{120,122,129,132,133,141,142,144,147,148,155,156}$ A meta-analysis has shown that HIV is associated with a 6.4-fold increased risk of osteopenia/low BMD and a threefold increased risk of osteoporosis. ${ }^{129}$ In a cross-sectional study of 120 women over the age of 40 years, those with HIV who were postmenopausal had a lower mental index and antegonial depth on panoramic jaw X-ray examination when compared to those without HIV, while premenopausal HIV-positive women only had lower antegonial depth than HIV-negative women. ${ }^{156}$ Yin et al have performed several studies demonstrating lower BMD in women with HIV (Table 4). In a cross-sectional study of HIVpositive, postmenopausal women, mean BMD in the lumbar spine and total hip were significantly lower when compared to historical matched controls. ${ }^{144}$ Additionally, those with HIV were more likely to have documented osteoporosis based on $\mathrm{T}$-scores at the lumbar spine (43\% vs $23 \%)$ and hip (10\% vs $1 \%$ ) when compared to the HIV-negative controls. ${ }^{144}$ In a longitudinal cohort of women in New York, adjusted analyses demonstrated that HIV-positivity was associated with lower BMD at the lumbar spine and total hip, and that women with HIV were also more likely to have higher levels of markers of bone turnover. ${ }^{132}$ However, this did not translate to a higher risk of fragility fracture in this population. ${ }^{132}$ In a subsequent study of HIV-positive and HIV-negative women, HIV status was not associated with an increased risk of fracture, nor was CD4 count or use of ART. ${ }^{149}$ While some studies have corroborated Yin et al's findings ${ }^{132,149}$ that fracture incidence does not increase with HIV, ${ }^{142}$ other studies have found evidence to the contrary. ${ }^{146,157-162}$ In a Canadian study of 137 HIV-positive patients and 402 HIV-negative controls, those with HIV had a 1.7-fold higher lifetime risk of fragility fracture. ${ }^{146}$ Similarly, association between bone loss and CD4 count among women with HIV has also been inconsistent. ${ }^{120,122,129,132,135,144,145,147,163-165}$

Antiretroviral therapy has been associated with a decline in BMD within the first 1-2 years of therapy. ${ }^{122,129,134,138,139,166-168}$ However, the relationship between long-term ART and bone health is not as clear, and bone loss may stabilize with ongoing therapy. ${ }^{120,128,138,147}$ In vitro studies have shown several antiretrovirals cause changes in bone metabolism; zidovudine (AZT), an NRTI, ${ }^{169}$ and ritonavir, a PI,${ }^{140}$ are associated with increased osteoclast activity, while TDF causes renal phosphate wasting and predisposes to osteoporosis. ${ }^{137,167,168,170,171}$ However, while TDF use has consistently been shown to cause bone loss, ${ }^{137,141,167,168,171}$ clinical studies examining other antiretrovirals have not necessarily confirmed the in vitro findings. ${ }^{141,147,167,172}$ For example, in a study of $300 \mathrm{HIV}$-positive women, ART use overall was not associated with a decrease in BMD, and AZT 


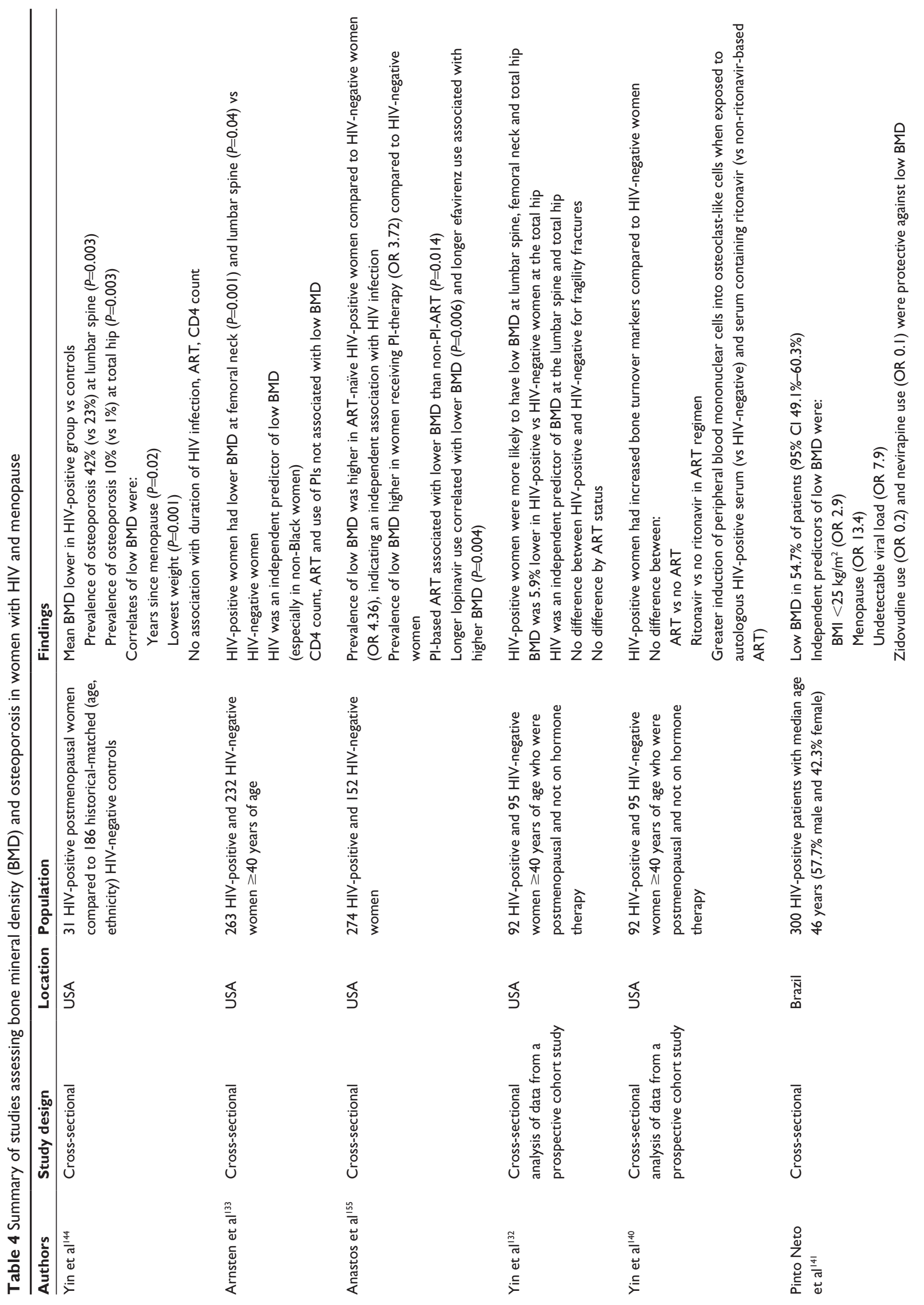



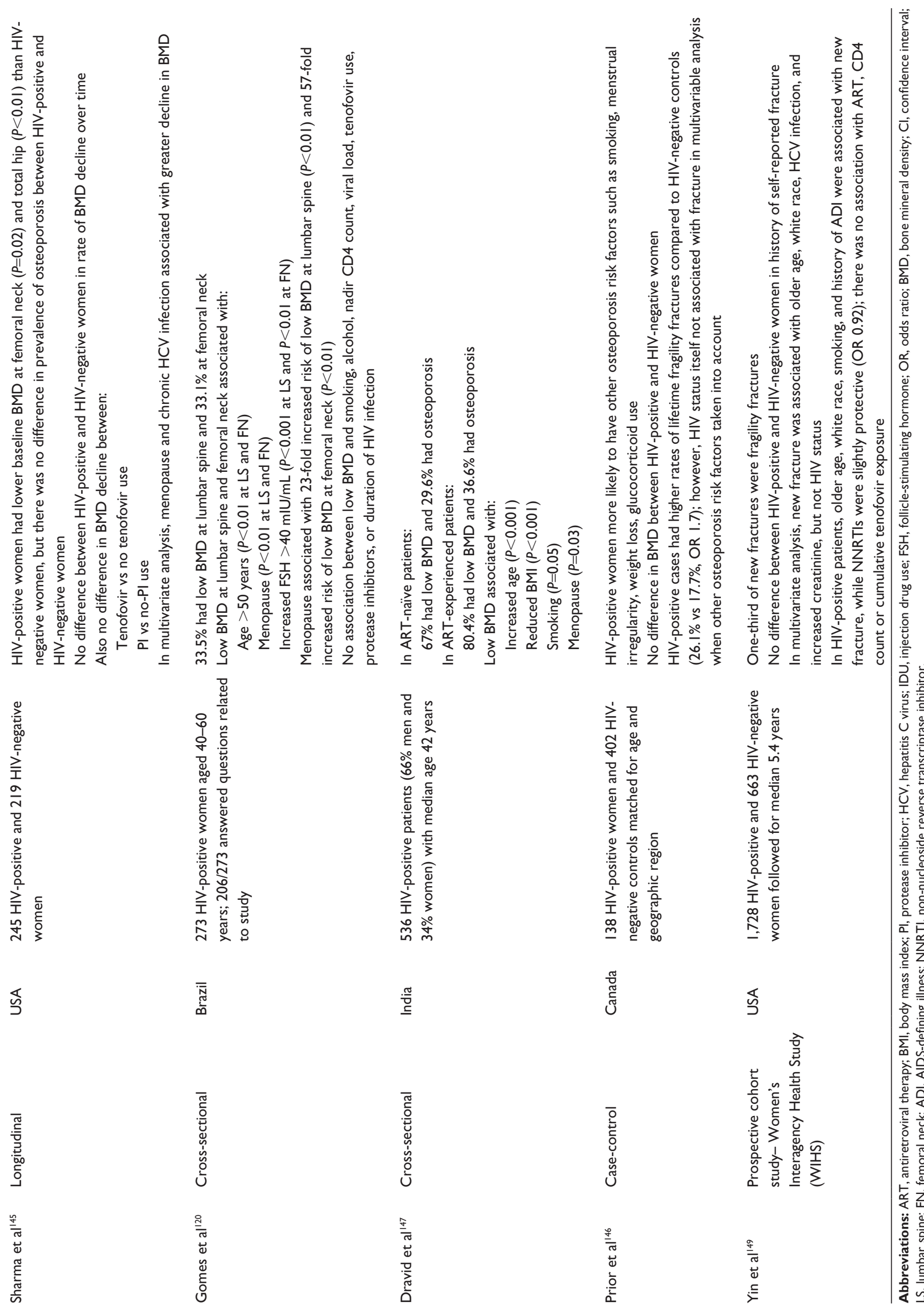

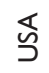

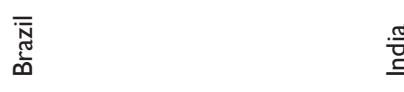

Uั
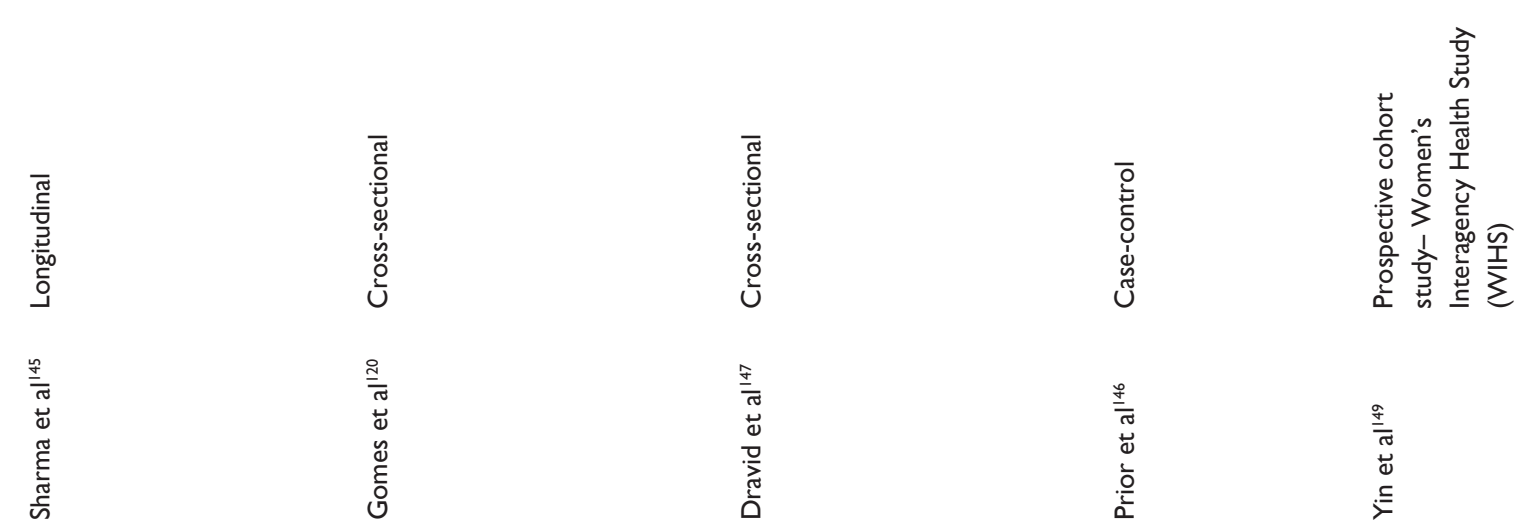

$\frac{7}{\frac{\pi}{0}}$
$\frac{0}{0}$
$\frac{0}{2}$

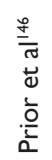

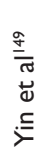


was found to be protective against bone loss. ${ }^{141}$ Another study found that NRTI use was associated with BMD decline. ${ }^{173}$ Similarly, the relationship between PIs and BMD is inconsist ent, ${ }^{120,128,134,145,155,167,174-177}$ while NNRTIs and integrase inhibitors, particularly raltegravir, appear to have less of an impact on bone health. ${ }^{122,137,149,178,179}$

Given that HIV is associated with changes in BMD, some experts suggest that HIV should be included in the list of medical conditions that cause secondary osteoporosis. ${ }^{131}$ However, regional osteoporosis guidelines vary in their recommendations regarding screening (Table 5). ${ }^{121,131,180,181}$ Most guidelines suggest that osteoporosis risk be estimated based on a comprehensive clinical tool (such as the Fracture Risk Assessment Tool [FRAX]) ${ }^{182}$ to calculate a 10 -year fracture risk (Table 6). ${ }^{123,131,183} \mathrm{HIV}$ is not included in this clinical tool. In 2015, specific guidelines were published for management of bone disease in individuals with HIV (Tables 5 and 7). ${ }^{131}$ These guidelines suggest that all HIVpositive individuals should be assessed for their fracture risk, based on the clinical tool suggested in their appropriate regional guideline. HIV-positive individuals with one major risk factor for osteoporosis (such as men $\geq 50$ years and postmenopausal women) should undergo screening with dual-energy X-ray absorptiometry (Table 6). ${ }^{131,134}$ If no major risk factor exists, patients should be assessed according to age-specific recommendations: for men and premenopausal women $\geq 40$ years of age, fracture risk should be calculated and those at intermediate-to-high risk should undergo dual-energy X-ray absorptiometry screening. ${ }^{131}$

With respect to management, those with HIV should be managed as per the general population, including both lifestyle modifications and pharmacologic therapy where appropriate (Table 7). Secondary causes of bone loss should be excluded. Many patients with HIV will have risk factors for vitamin D deficiency, and should be assessed for supplementation if insufficiency or deficiency exists. ${ }^{122,131,184}$ Bisphosphonates do not have significant interactions with ART and are considered safe for use in those with HIV. ${ }^{122}$ Alendronate and zoledronic acid are the preferred agents in HIV as they have been evaluated and found to be effective in this population. ${ }^{122,131,185-190}$ If bisphosphonates cannot be used, teriparatide is the suggested second-line agent, though it has not been specifically studied in patients with HIV. ${ }^{122,134}$ For the most part, the benefits of ART with respect to virologic control are considered to outweigh the risks of potentially exacerbating bone loss. However, in those patients who are at high risk of fracture based on a comprehensive clinical

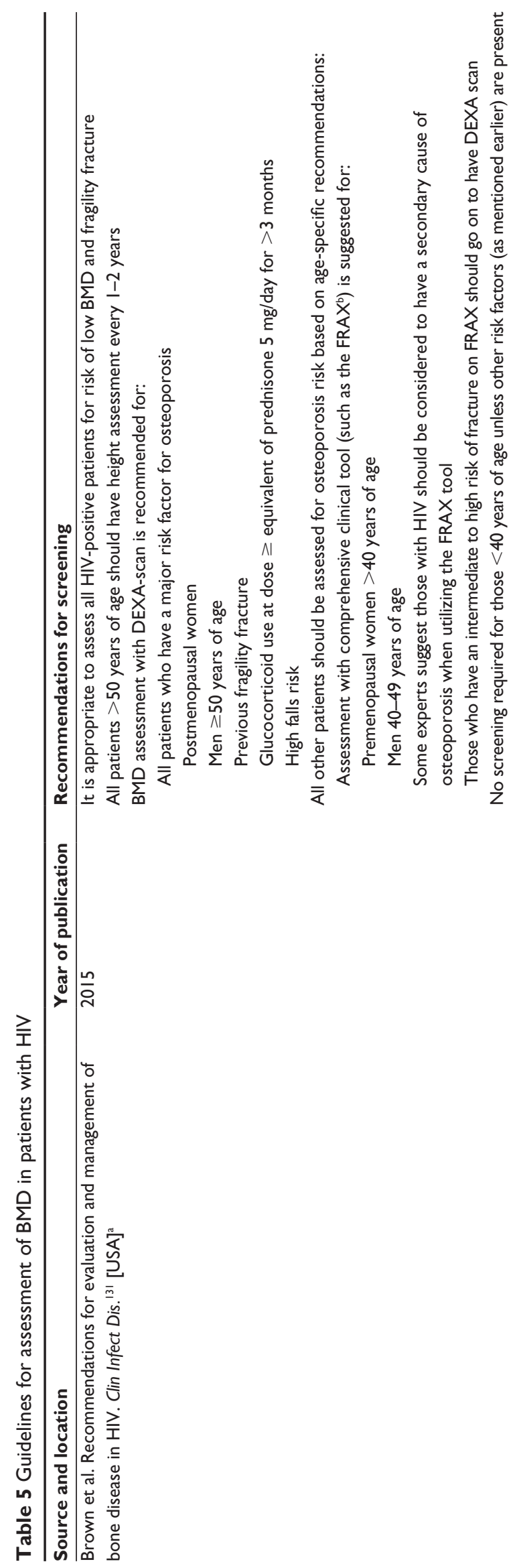




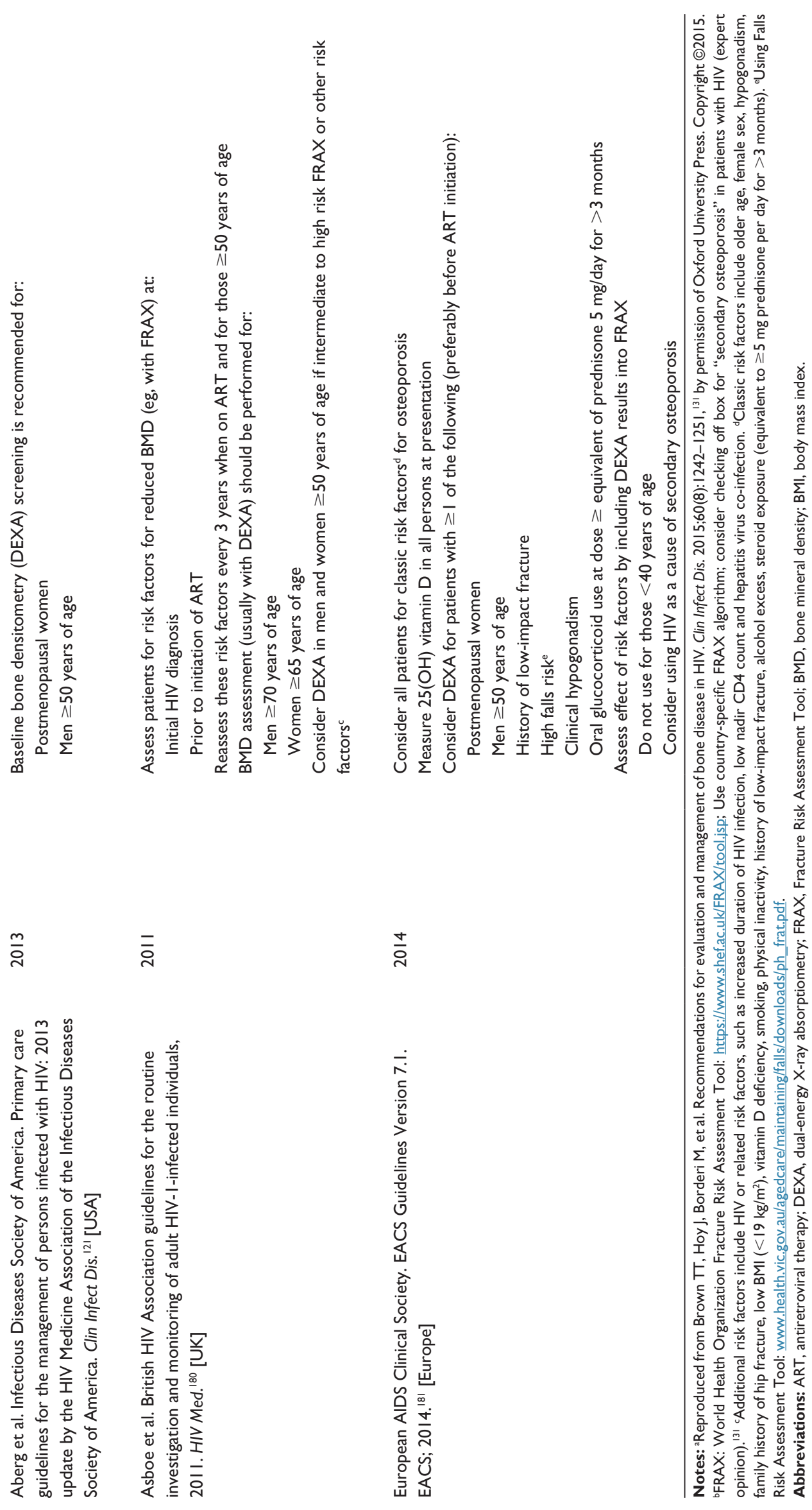


Table 6 Interpretation of fracture risk assessment and DEXA scores in assessment of bone disease

\begin{tabular}{lll}
\hline Source & Result & Interpretation \\
\hline Risk of Fracture $^{\mathrm{a}}$ & $\leq 10 \%$ risk of major osteoporotic fracture in 10 years & Low risk \\
& $10 \%-20 \%$ risk of major osteoporotic fracture in 10 years & Moderate risk \\
& $\geq 20 \%$ risk of major osteoporotic fracture in 10 years and/or $\geq 3 \%$ risk of hip fracture & High risk \\
DEXA scan ${ }^{\mathrm{b}}$ & T-score $>-1.0$ & Within normal limits \\
& T-score $\leq-1.0$ but $>-2.5$ & Osteopenia \\
& T-score $\leq-2.5$ & Osteoporosis \\
\hline
\end{tabular}

Notes: ${ }^{a}$ Based on a validated clinical tool such as the FRAX ${ }^{182}$ or the Canadian Association of Radiologists and Osteoporosis Canada (CAROC) tool. ${ }^{123}$ bUse T-scores for postmenopausal women and men aged $\geq 50$ years; use $z$ scores for patients aged $<50$ years; based on the femoral neck score. ${ }^{124}$ Reproduced from Brown TT, Hoy J, Borderi M, et al. Recommendations for evaluation and management of bone disease in HIV. Clin Infect Dis. 20I5;60(8): I242-I25I, ${ }^{131}$ by permission of Oxford University Press. Copyright $@ 2015$.

Abbreviations: FRAX, Fracture Risk Assessment Tool; DEXA, dual-energy X-ray absorptiometry.

Table 72015 Guidelines for management of bone disease in patients with HIV

\begin{tabular}{|c|c|c|c|c|}
\hline Source & $\begin{array}{l}\text { Year of } \\
\text { publication }\end{array}$ & Patient population & $\begin{array}{l}\text { Recommendation for } \\
\text { repeat screening }\end{array}$ & $\begin{array}{l}\text { Recommendations for } \\
\text { management }\end{array}$ \\
\hline $\begin{array}{l}\text { Brown et al. } \\
\text { Recommendations } \\
\text { for evaluation and } \\
\text { management of } \\
\text { bone disease in HIV. } \\
\text { Clin Infect Dis. }{ }^{\mid 31}\end{array}$ & 2015 & Patients younger than 40 years & $\begin{array}{l}\text { No routine screening } \\
\text { suggested; assess when } \\
\text { develop major risk factor or } \\
\text { become }>40 \text { years of age }\end{array}$ & $\begin{array}{l}\text { All patients: } \\
\text { Adequate calcium intake } \\
\text { Adequate vitamin levels and } \\
\text { supplementation if required } \\
\text { Lifestyle modifications } \\
\text { Smoking and alcohol } \\
\text { cessation } \\
\text { Falls prevention } \\
\text { Exercise }\end{array}$ \\
\hline
\end{tabular}

$\begin{array}{ll}\begin{array}{l}\text { Patients aged 40-50 years with a } \\ \text { low 10-year fracture risk based } \\ \text { on FRAX (no DEXA required) }\end{array} & \begin{array}{l}\text { Monitor FRAX every } \\ 2-3 \text { years }\end{array} \\ \begin{array}{ll}\text { Patients with moderate 10-year } \\ \text { fracture risk: }\end{array} & \begin{array}{l}\text { Repeat DEXA in I-2 years } \\ \text { if advanced osteopenia } \\ \text { FRAX } \geq 10 \% \text { but }<20 \%\end{array} \\ \begin{array}{l}\text { (T-score between }-2.00 \\ \text { and }-2.49)\end{array} \\ \begin{array}{l}\text { No history of hip or vertebral } \\ \text { fracture }\end{array} & \begin{array}{l}\text { mepeat DEXA in } 5 \text { years if } \\ \text { between }-1.00 \text { and }-1.99)\end{array} \\ & \text { Repeat DEXA in } 2 \text { years }\end{array}$

osteoporosis:

Patients with high 10-year

fracture risk ${ }^{\mathrm{a}}$

T-score $<2.5$ at FN, TH or LS

on DEXA scan

Previous hip or vertebral

fracture
Monitor FRAX every

Repeat DEXA in 2 years

\author{
Exclude secondary causes of \\ osteoporosis $^{c}$ \\ Treat osteoporosis as per \\ general population: \\ Bisphosphonates first-line \\ therapy (alendronate or \\ zoledronic acid preferred) \\ Review therapy at $3-5$ years \\ Consider avoiding TDF or \\ boosted PIs if low BMD or \\ osteoporosis (but benefits of \\ ART outweigh risks)
}

Notes: ${ }^{2} \geq 20 \%$ risk of major osteoporotic fracture in 10 years and/or $\geq 3 \%$ risk of hip fracture (with or without incorporation of BMD result); based on validated clinical tool such as the FRAX. ${ }^{b}$ Check vitamin D levels in those with low BMD or previous fracture or risk factors for vitamin D deficiency (dark skin, sun avoidance, malabsorption, obesity, chronic kidney disease, or on treatment with efavirenz); supplemental vitamin D if deficient and target level $>30 \mu \mathrm{g} / \mathrm{L}$. 'Secondary causes of osteoporosis include: type I diabetes mellitus, osteogenesis imperfecta in adults, untreated long-standing hyperthyroidism, hypogonadism, or premature menopause ( $<45$ years), chronic malnutrition, malabsorption, and chronic liver disease. Reproduced from Brown TT, Hoy J, Borderi M, et al. Recommendations for evaluation and management of bone disease in HIV. Clin Infect Dis. 2015;60(8): I242-125I, ${ }^{131}$ by permission of Oxford University Press. Copyright $\odot 2015$.

Abbreviations: BMD, bone mineral density; ART, antiretroviral therapy; PIs, protease inhibitors; TDF, tenofovir disoproxil fumarate $\left(\right.$ Viread $\left.^{\circledR}\right)$; FN, femoral neck; TH, total hip; LS, lumbar spine; FRAX, Fracture Risk Assessment Tool; DEXA, dual-energy X-ray absorptiometry. 
assessment, clinicians may consider avoiding TDF or PIs if reasonable alternatives are available. ${ }^{131,134}$

\section{Future directions}

While the body of evidence continues to grow, further research regarding the complex interaction between HIV and menopause is needed. Larger studies are required to determine if menopause affects antiretroviral pharmacokinetics and response to therapy. The influence of menopause on cervico-vaginal shedding of the HIV virus may have implications for risk of transmission and should be further evaluated. It will also be important to determine if earlier self-report of menopause is truly due to an earlier age of onset in women with HIV, or is confounded by a higher risk of amenorrhea without menopause. Therefore, future studies should consider including biochemical confirmation of menopause in order to better define this relationship. There are currently no studies specifically examining the efficacy and safety of HT in women with HIV, which likely contributes to underuse in this population. Finally, ongoing monitoring of bone health in the context of newer antiretrovirals, particularly with the introduction of tenofovir alafenamide fumarate, will be important to ensure that women are on safe and optimal antiretroviral regimens as they transition through menopause.

\section{Conclusion}

Menopause is a pivotal life event for women, but each individual woman will have her own unique experience of the process. $\mathrm{HIV}$ infection is potentially associated with an increased risk of earlier menopause, more prevalent and pronounced menopausal symptoms, and likely exacerbates the changes in bone health that accompany the menopausal transition. Increasing age and menopause do not result in a cessation of sexual activity, but can affect the degree to which individuals perceive themselves to be at risk of transmitting and acquiring HIV infection, and can influence their engagement in safe sexual practices. Therefore, as patients with HIV live longer in the era of effective cART, the management of HIV infection will continue to increase in complexity. This management must occur in conjunction with the screening and management guidelines for age-related comorbidities, and must include an evaluation of the potential interactions between HIV, sexual behaviors, and other pivotal life events, including menopause.

\section{Disclosure}

The authors have no conflicts of interest to disclose in this work.

\section{References}

1. Palella FJ Jr, Delaney KM, Moorman AC, et al. Declining morbidity and mortality among patients with advanced human immunodeficiency virus infection. HIV Outpatient Study Investigators. $N$ Engl $J$ Med. 1998;338(13):853-860.

2. Antiretroviral Therapy Cohort Collaboration. Life expectance of individuals on combination antiretroviral therapy in high-income countries: a collaborative analysis of 14 cohort studies. Lancet. 2008; 372(9635):293-299.

3. Harrison KM, Song R, Zhang X. Life expectancy after HIV diagnosis based on national HIV surveillance data from 25 states, United States. J Acquir Immune Defic Syndr. 2010;53(1):124-130.

4. Lima VD, Hogg RS, Harrigan PR, et al. Continued improvement in survival among HIV-infected individuals with newer forms of highly active antiretroviral therapy. AIDS. 2007;21(6):685-692.

5. Samji H, Cescon A, Hogg RS, et al. Closing the gap: increases in life expectancy among treated HIV-positive individuals in the United States and Canada. PLoS One. 2013;8(12):e81355.

6. Joint United Nations Programme on HIV/AIDS (UNAIDS). Global report: UNAIDS report on the global AIDS epidemic 2013. Joint United Nations Programme on HIV/AIDS (UNAIDS); 2013. Available from: http://www.unaids.org/sites/default/files/en/media/unaids/ contentassets/documents/epidemiology/2013/gr2013/UNAIDS_ Global_Report_2013_en.pdf. Accessed November 16, 2015.

7. Centers for Disease Control and Prevention [homepage on the Internet]. HIV Among Women. Division of HIV/AIDS Prevention, National Center for HIV/AIDS, Viral Hepatitis, Sexually Transmitted Diseases and Tuberculosis Prevention: US Department of Health and Human Services. Available from: http://www.cdc.gov/hiv/group/gender/women/ index.html\#refa. Updated June 23, 2015. Accessed November 16, 2015.

8. Public Health Agency of Canada. HIV and AIDS in Canada: Surveillance Report to December 31, 2013. Minister of Public Works and Government Services Canada; 2014. Public Health Agency of Canada; 2014. Available from: http://www.phac-aspc.gc.ca/aids-sida/ publication/survreport/2013/dec/assets/pdf/hiv-aids-surveillence-eng. pdf. Accessed November 16, 2015.

9. Cejtin HE. Care of the Human immunodeficiency virus-infected menopausal woman. Am J Obstet Gynecol. 2012;207(2):87-93.

10. Kanapathipillai R, Hickey M, Giles M. Human immunodeficiency virus and menopause. Menopause. 2013;20(9):983-990.

11. Centers for Disease Control and Prevention [homepage on the Internet] HIV Among People Aged 50 and Over. Division of HIV/AIDS Prevention, National Center for HIV/AIDS, Viral Hepatitis, Sexually Transmitted Diseases and Tuberculosis Prevention: US Department of Health and Human Services. Available from: http://www.cdc.gov/hiv/ group/age/olderamericans/index.html. Updated May 12, 2015. Accessed November 16, 2015.

12. American Psychological Association [homepage on the Internet] Karpiak S. Adherence to antiretroviral therapy (ART) in older adults living with HIV/AIDS. American Psychological Association; 2014. Available from: http://www.apa.org/pi/aids/resources/exchange/2014/01/ anti-retroviral-therapy.aspx. Accessed November 16, 2015.

13. Fantry LE, Zhan M, Taylor GH, Sill AM, Flaws JA. Age of menopause and menopausal symptoms in HIV-infected women. AIDS Patient Care STDS. 2005;19(11):703-711.

14. World Health Organization. WHO Scientific Group on Research on the Menopause in the 1990's. WHO Technical Report Series 866, Geneva, Switzerland; 1996. Available from: http://apps.who.int/iris/ bitstream/10665/41841/1/WHO_TRS_866.pdf. Accessed November $16,2015$.

15. International Menopause Society [homepage on the Internet]. Menopause Terminology. International Menopause Society. Available from: http://www.imsociety.org/menopause_terminology.php. Accessed November 16, 2015. 
16. Brambilla DJ, McKinlay SM. A prospective study of factors affecting age at menopause. J Clin Epidemiol. 1989;42(11):1031-1039.

17. McKinlay SM, Bifano NL, McKinlay JB. Smoking and age at menopause in women. Ann Intern Med. 1985;103(3):350-356.

18. Conde DM, Pinto-Neto AM, Costa-Paiva L. Age at menopause of HIVinfected women: a review. Gynecol Endocrinol. 2008;24(2):84-86.

19. Calvet GA, Grinsztejn BG, Quintana MS, et al. Predictors of early menopause in HIV-infected women: a prospective cohort study. Am J Obstet Gynecol. 2015;212(6):765.e1-e13.

20. Thomas F, Renaud F, Benefice E, de Meeus T, Guegan JF. International variability of ages at menarche and menopause: patterns and main determinants. Hum Biol. 2001;73(2):271-290.

21. Harlow SD, Gass M, Hall JE, et al. Executive summary of the stages of reproductive aging workshop +10 : addressing the unfinished agenda of staging reproductive aging. Menopause. 2012;19(4):387-395.

22. Shuster LT, Rhodes DJ, Gostout BS, Grossardt BR, Rocca WA. Premature menopause or early menopause: long-term health consequences. Maturitas. 2010;65(2):161-166.

23. Fan MD, Maslow BS, Santoro N, Schoenbaum E. HIV and menopause. Menopause Int. 2008;14(4):163-168.

24. Blumel JE, Castelo-Branco C, Binfa L, et al. Quality of life after the menopause: a population study. Maturitas. 2000;34(1):17-23.

25. Conde DM, Pinto-Neto AM, Santos-Sa D, Costa-Paiva L, Martinez EZ. Factors associated with quality of life in a cohort of postmenopausal women. Gynecol Endocrinol. 2006;22(8):441-446.

26. Utian WH. Psychosocial and socioeconomic burden of vasomotor symptoms in menopause: a comprehensive review. Health Qual Life Outcomes. 2005;3:47.

27. Lui-Filho JF, Valadares ALR, Gomes DC, Amaral E, Pinto-Neto AM, Costa-Paiva L. Menopausal symptoms and associated factors in HIVpositive women. Maturitas. 2013;76(2):172-178.

28. Kojic EM, Wang CC, Cu-Uvin S. HIV and menopause: a review. $J$ Womens Health (Larchmt). 2007;16(10):1402-1411.

29. Zapantis G, Santoro N. The menopausal transition: characteristics and management. Best Pract Res Clin Endocrinol Metab. 2003;17(1):33-52.

30. Zablotsky D, Kennedy M. Risk factors and HIV transmission to midlife and older women: knowledge, options, and the initiation of safer sexual practices. J Acquir Immune Defic Syndr. 2003;33 Suppl 2: S122-S130.

31. Althoff KN, Gebo KA, Gange SJ, et al. CD4 count at presentation for HIV care in the United States and Canada: are those over 50 years more likely to have a delayed presentation? AIDS Res Ther. 2010;7:45.

32. Samuel MI, Welch J, Tenant-Flowers M, Poulton M, Campbell L, Taylor C. Care of HIV-positive women aged 50 and over - can we do better? Int J STD AIDS. 2014;25(4):303-305.

33. Duffus WA, Kettinger L, Stephens T, et al. Missed opportunities for earlier diagnosis of HIV infection - South Carolina, 1997-2005. MMWR Morb Mortal Wkly Rep. 2006;55(47):1269-1272.

34. Duffus WA, Weis K, Kettinger L, Stephens T, Albrecht H, Gibson JJ. Riskbased HIV testing in South Carolina health care settings failed to identify the majority of infected individuals. AIDS Patient Care STDS. 2009; 23(5):339-345.

35. World Health Organization. WHO case definitions of HIV for surveillance and revised clinical staging and immunological classification of HIV-related disease in adults and children. WHO; 2007. Available from: http://www.who.int/hiv/pub/guidelines/HIVstaging150307.pdf. Accessed November 16, 2015.

36. Taylor TN, Weedon J, Golub ET, et al. Longitudinal trends in sexual behaviors with advancing age and menopause among women with and without HIV-1 infection. AIDS Behav. 2015;19(5):931-940.

37. Lindau ST, Schumm LP, Laumann EO, Levinson W, O'Muircheartaigh CA, Waite LJ. A study of sexuality and health among older adults in the United States. N Engl J Med. 2007;357(8):762-774.

38. Waite LJ, Laumann EO, Das A, Schumm LP. Sexuality: measures of partnerships, practices, attitudes, and problems in the national social life, health and aging study. J Gerontol B Psychol Sci Soc Sci. 2009;64 Suppl 1:i56-i66.
39. Laumann EO, Gagnon JH, Michael RT, et al. The social organization of sexuality: sexual practices in the United States. Chicago: The University of Chicago Press; 1994.

40. Dunn ME, Cutler N. Sexual issues in older adults. AIDS Patient Care STDS. 2000;14(2):6-69.

41. Rosen RG, Taylor JFG, Leiblum SR, Bachmann GA. Prevalence of sexual dysfunction in women: results of a survey study of 329 patients in an outpatient gynecological clinic. J Sex Marital Ther. 1994;19(3):171-188.

42. Bachmann GA. Influence of menopause on sexuality. Int J Fertil Menopausal Stud. 1995;40 Suppl 1:16-22.

43. Diaz T, Schable B, Chu SY. Relationship between use of condoms and other forms of contraception among human immunodeficiency virus-infected women. Supplement to HIV and AIDS Surveillance Project Group. Obstet Gynecol. 1995;86(2):277-282.

44. Wilson TE, Koenig LJ, Walter E, et al. Dual contraceptive method use for pregnancy and disease prevention among HIV-infected and HIV-uninfected women: the importance of an event-level focus for promoting safer sexual behaviors. Sex Transm Dis. 2003;30(11):809-812.

45. Schick V, Herbenick D, Reece M, et al. Sexual behaviors, condom use, and sexual health of Americans over 50: implications for sexual health promotion for older adults. $J$ Sex Med. 2010;7 Suppl 5:315-329.

46. Schable B, Chu SY, Diaz T. Characteristics of women 50 years of age or older with heterosexually acquired AIDS. Am J Public Health. 1996;86(11):1616-1618.

47. Adekeye OA, Heiman HJ, Onyeabor OS, Hyacinth HI. The new invincibles: HIV screening among older adults in the U.S. PLoS One. 2012;7(8):e43618.

48. Wigfall LT, Richter DL, Torres ME, et al. HIV testing among midlife women in the deep south: an analysis of the 2008 behavioral risk factor surveillance system survey data. $J$ Women's Health (Larchmt). 2011;20(6):933-941.

49. Skiest DJ, Keiser P. Human immunodeficiency virus infection in patients older than 50 years. A survey of primary care physicians' beliefs, practices and knowledge. Arch Fam Med. 1997;6(3):289-294.

50. Akers AY, Bernstein L, Doyle J, Corbie-Smith G. Older women and HIV testing: examining the relationship between HIV testing history, age, and lifetime HIV risk behaviors. Sex Transm Dis. 2008;35(4):420-423.

51. Bachmann GA, Leiblum SR. The impact of hormones on menopasual sexuality: a literature review. Menopause. 2004;11(1):120-123.

52. Senanyake P. Women and reproductive health in a graying world. Int J Gynecol Obstet. 2000;70(1):59-67.

53. Golub SA, Tomassilli JC, Pantalone DW, Brennan M, Karpiak SE, Parsons JT. Prevalence and correlates of sexual behavior and risk management among HIV-positive adults over 50. Sex Transm Dis. 2010;37(10): $615-620$.

54. Massad LS, Evans CT, Wilson TE, et al. Impact of menopause on condom use by HIV-seropositive and comparison seronegative women. J Acquir Immune Defic Syndr. 2008;47(3):401-402.

55. Psaros C, Barinas J, Robbins GK, Bedoya CA, Safren SA, Park ER. Intimacy and sexual decision making: exploring the perspective of HIV positive women over 50. AIDS Patient Care STDS. 2012;26(12):755-760.

56. Emlet CA. "You're awfully old to have this disease": experiences of stigma and ageism in adults 50 years and older living with HIV/AIDS. Gerontologist. 2006;46(6):781-790.

57. Massad LS, Evans CE, Wilson TE, et al. Contraceptive use among U.S. women with HIV. J Women's Health (Larchmt). 2007;16(5):657-666.

58. World Health Organization. World Health Organization brief on antiretroviral treatment (ART) in HIV and TB prevention. WHO; 2011. Available from: http://www.princeton.edu/cbli/student-projects-1/ WHO-brief-on-ART-and-Community-Viral-Load-jan_2011.pdf. Accessed November 16, 2015.

59. Attia S, Egger M, Muller M, Zwahlen M, Low N. Sexual transmission of HIV according to viral load and antiretroviral therapy: a systematic review and meta-analysis. AIDS. 2009;23(11):1397-1404.

60. Rollenhagen C, Asin SN. Enhanced HIV-1 replication in ex vivo ectocervical tissues from post-menopausal women correlates with increased inflammatory responses. Mucosal Immunol. 2011;4(6):671-681. 
61. Melo KC, Melo MR, Ricci BV, Segurado AC. Correlates of human immunodeficiency virus cervicovaginal shedding among postmenopausal and fertile-aged women. Menopause. 2012;19(2):150-156.

62. Valdiglesias V, Sanchez-Flores M, Maseda A, et al. Lymphocyte subsets in a population of nonfrail elderly individuals. J Toxicol Environ Health A. 2015;78(13-14):790-804.

63. Balestre E, Eholie SP, Lokossue A, et al. Effect of age on immunological response in the first year of antiretroviral therapy in HIV-1-infected adults in West Africa. AIDS. 2012;26(8):951-957.

64. Grabar S, Kousignian I, Sobel A, et al. Immunologic and clinical responses to highly active antiretroviral therapy over 50 years of age. Results from the French Hospital Database on HIV. AIDS. 2004;18(15):2029-2038.

65. Manfredi R, Chiodo F. A case-control study of virological and immunological effects of highly active antiretroviral therapy in HIV-infected patients with advanced age. AIDS. 2000;14(10):1475-1477.

66. Van Benthem BH, Vernazza P, Coutinho RA, Prins M; European Study on the Natural History of HIV Infection in Women and the Swiss HIV Cohort Study. The impact of pregnancy and menopause on CD4 lymphocyte counts in HIV-infected women. For the European Study on the Natural History of HIV Infection in Women and the Swiss HIV Cohort Study. AIDS. 2002;16(6):919-924.

67. Patterson KB, Cohn SE, Uyanik J, Hughes M, Smurzynski M, Eron JJ. Treatment responses in antiretroviral treatment (ART) naïve pre- and post-menopausal HIV-infected women: an analysis from ACTG studies. Clin Infect Dis. 2009;49(3):473-476.

68. Calvet GA, Velasque L, Luz PM, et al. Absence of effect of menopause status at initiation of first-line antiretroviral therapy on immunologic or virologic responses: a cohort study from Rio de Janeiro, Brazil. PLoS One. 2014;9(2):e89299.

69. Dumond JB, Adams JL, Prince HM, et al. Pharmacokinetics of two common antiretroviral regimens in older HIV-infected patients: a pilot study. HIV Med. 2013;14(7):401-409.

70. Gervasoni C, Meraviglia P, Landonio S, et al. Tenofovir plasma concentrations in post-menopausal versus pre-menopausal HIV-infected women. J Antimicrob Chemother. 2013;68(5):1206-1207.

71. Cottrell ML, Patterson KB, Prince HM, et al. Effect of HIV-infection and menopause status on raltegravir pharmacokinetics in the blood and genital tract. Antivir Ther. Epub 2015 Jun 3.

72. Baxi SM, Greenblatt RM, Bacchetti P, et al. Common clinical conditions age, low BMI, ritonavir use, mild renal impairment - affect tenofovir pharmacokinetics in a large cohort of HIV-infected women. AIDS. 2014; 28(1):59-66.

73. Orlando G, Meraviglia P, Cordier L, et al. Antiretroviral treatment and age-related comorbidities in a cohort of older, HIV-infected patients. HIV Med. 2006;7(8):549-557.

74. de Pommerol M, Hessamfer M, Lawson-Ayayi S, et al. Menopause and HIV infection: age at onset and associated factors. Int J STD AIDS. 2011;22(2):67-72.

75. Cooper GS, Sandler DP. Age at natural menopause and mortality. Ann Epidemiol. 1998;8(4):229-235.

76. Jacobsen BK, Heuch I, Kvale G. Age at natural menopause and all-cause mortality: a 37-year follow-up of 19,731 Norwegian women. Am J Epidemiol. 2003;157(10):923-929.

77. Grady D, Sawaya GF. Discontinuation of postmenopausal hormone therapy. Am J Med. 2005;118 Suppl 12B:163-165.

78. Soares CN. Practical strategies for diagnosing and treating depression in women: menopausal transition. J Clin Psychiatry. 2008;69(10):e30.

79. Santoro N, Fan M, Maslow B, Schoenbaum E. Women and HIV infection: the makings of a midlife crisis. Maturitas. 2009;64(3):160-164.

80. Ferreira CE, Pinto-Neto AM, Marques Conde D, Costa-Paiva L, Morais SS Magalhaes J. Menopause symptoms in women infected with HIV: prevalence and associated factors. Gynecol Endocrinol. 2007;23(4):198-205.

81. Schoenbaum EE, Hartel D, Lo Y, et al. HIV infection, drug use, and onset of natural menopause. Clin Infect Dis. 2005;41(10):1517-1524.

82. Boonyanurak P, Bunupuradah T, Wilawan K, et al. Age at menopause and menopause-related symptoms in human immunodeficiency virusinfected Thai women. Menopause. 2012;19(7):820-824.
83. Imai K, Sutton MY, Mdodo R, del Rio C. HIV and menopause: a systematic review of the effects of HIV infection on age at menopause and the effects of menopause on response to antiretroviral therapy. Obstet Gynecol Int. 2013;2013:340309.

84. Clark RA, Cohn SE, Jarek C, et al. Perimenopausal symptomatology among HIV-infected women at least 40 years of age. J Acquir Immune Defic Syndr. 2000;23(1):99-100.

85. Cejtin HE, Kalinowski A, Bacchetti P, et al. Effects of human immunodeficiency virus on protracted amenorrhea and ovarian dysfunction. Obstet Gynecol. 2006;108(6):1423-1431.

86. Rozenbaum H. Menopause et regles en 2001. Resultats de l'enquete CLIMATS. Reprod Hum Hormones. 2002;15:11-22. French.

87. Cejtin SH, Taylor R, Watts DH. Assessment of menopausal status among women in the Women's Interagency HIV Study (WIHS). In: Proceedings of the 57th International AIDS Conference; July 11-16, 2004; Bangkok, Thailand.

88. Gold EB, Bromberger J, Crawford S, et al. Factors associated with age at natural menopause in a multiethnic sample of midlife women. Am J Epidemiol. 2001;153(9):865-874.

89. Bromberger JT, Matthews KA, Kuller LH, Wing RR, Meilahn EN, Platinga P. Prospective study of the determinants of age at menopause. Am J Epidemiol. 1997;145(2):124-133.

90. MacMahon B, Worcester J. Age at menopause. United States 1960-1962. Vital Health Stat 11. 1966;(19):1-20.

91. Clark RA, Mulligan K, Stamenovic E, et al. Frequency of anovulation and early menopause among women enrolled in selected AIDS clinical trials group studies. J Infect Dis. 2001;184(10):1325-1327.

92. Shah PN, Smith JR, Wells C, et al. Menstrual symptoms in women infected by the human immunodeficiency virus. Obstet Gyencol. 1994;83(3): 397-400.

93. Harlow SD, Schuman P, Cohen M, et al. Effect of HIV infection on menstrual cycle length. J Acquir Immune Defic Syndr. 2000; 24(1):68-75.

94. Miller SA, Santoro N, Lo Y, et al. Menopause symptoms in HIVinfected and drug-using women. Menopause. 2005;12(3):348-356.

95. Enriquez M, Lackey N, Witt J. Health concerns of mature women living with HIV in the Midwestern United States. J Assoc Nurses AIDS Care. 2008;19(1):37-46.

96. Tuchman E. Menopause symptom attribution among midlife women in methadone treatment. Soc Work Health Care. 2010;49(1):53-67.

97. Looby SE, Shifren J, Corless I, et al. Increased hot flash severity and related interference in perimenopausal human immunodeficiency virus-infected women. Menopause. 2014;21(4):403-409.

98. Johnson TM, Cohen HW, Santoro N, et al. Attribution of menopause symptoms in human immunodeficiency virus-infected or at-risk drugusing women. Menopause. 2008;15(3):551-557.

99. Rubin LH, Sundermann EE, Cook JA, et al. Investigation of menopausal stage and symptoms on cognition in human immunodeficiency virus-infected women. Menopause. 2014;21(9):997-1006.

100. Tuchman E, Pennington LE, Kull RM, Daneshyar S. Relationship between menopause symptoms and HIV risk among midlife women in methadone treatment: a pilot study. Subst Use Misuse. 2013;48(9): 711-718.

101. Tuchman E. Exploring the prevalence of menopause symptoms in midlife women in methadone maintenance treatment. Soc Work Health Care. 2007;45(4):43-62.

102. Maki PM, Rubin LH, Cohen M, et al. Depressive symptoms are increased in the early perimenopausal stage in ethnically diverse HIV+ and HIV-women. Menopause. 2012;19(11):1215-1223.

103. Morrison MF, Petitto JM, Ten Have T, et al. Depressive and anxiety disorders in women with HIV infection. Am J Psychiatry. 2002;159(5): 789-796.

104. Atkinson JH, Grant I. Natural history of neuropsychiatric manifestations of HIV disease. Psychiatr Clin North Am. 1994;17(1):17-33.

105. Lyketsos CG, Hoover DR, Guccione M, et al. Changes in depressive symptoms as AIDS develops. The multi-center AIDS cohort study. Am J Psychiatry. 1996;153(11):1430-1437. 
106. Moore J, Schuman P, Schoenbaum E, Boland B, Solomon L, Smith D. Severe adverse life events and depressive symptoms among women, or at risk for, HIV infection in four cities in the United States of America. AIDS. 1999;13(17):2459-2468.

107. Sorlini ML, Foca E, Motta D, et al. Elderly women with human immunodeficiency virus infection: is there an effect of the virus on neuropsychological profile? J Am Geriatr Soc. 2014;62(1): 194-196.

108. Bromberger JT, Assmann SF, Avis NE, Schocken M, Kravitz HM, Cordal A. Persistent mood symptoms in a multi-ethnic community cohort of pre- and perimenopausal women. Am J Epidemiol. 2003;158(4): 347-356.

109. Bromberger JT, Matthews KA, Schott LL, et al. Depressive symptoms during the menopausal transition: the Study of Women's Health Across the Nation (SWAN). J Affect Disord. 2007;103(1-3):267-272.

110. Bromberger JT, Kravitz HJ, Chang YF, Cyranowski JM, Brown C, Matthews KA. Major depression during and after the menopausal transition: Study of Women's Health Across the Nation (SWAN). Psychol Med. 2011;41(9):1879-1888.

111. Mohyi D, Tabassi K, Simon J. Differential diagnosis of hot flashes. Maturitas. 1997;27(3):203-214.

112. Hartel D, Lo Y, Bauer C, et al. Attitudes toward menopause in HIV-infected and at-risk women. Clin Interv Aging. 2008;3(3): 561-566.

113. Cook JA, Cohen MH, Burke J, et al. Effects of depressive symptoms and mental health quality of life on use of highly active antiretroviral therapy among HIV-seropositive women. J Acquir Immune Defic Syndr. 2002;30(4):401-409.

114. Cook JA, Grey D, Burke J, et al. Depressive symptoms and AIDSrelated mortality among a multisite cohort of HIV-positive women. Am J Public Health. 2004;94(7):1133-1140.

115. Tedaldi EM, Minniti NL, Fischer T. HIV-associated neurocognitive disorders: the relationship of HIV infection with physical and social comorbidities. Biomed Res Int. 2015;2015:641913.

116. Marques Conde D, Silva ET, Amaral WN, et al. HIV, reproductive aging, and health implications in women: a literature review. Menopause. 2009;16(1):199-213.

117. Richardson JL, Martin EM, Jimenez N, et al. Neuropsychological functioning in a cohort of HIV infected women: importance of antiretroviral therapy. J Int Neuropsychol Soc. 2002;8(6):781-793.

118. Freeman EW, Sammel MD, Lin H, Nelson DB. Associations of hormones and menopausal status with depressed mood in women with no history of depression. Arch Gen Psychiatry. 2006;63(4): 375-382.

119. Lindsay R, Hart DM, Aitken JM, MacDonald EB, Anderson JB, Clarke AC. Long-term prevention of postmenopausal osteoporosis by oestrogen: evidence for increased bone mass after delayed onset of oestrogen treatment. Lancet. 1976;1(7968):1038-1040.

120. Gomes DC, Valadares AL, de Moraes MJ, Lagrutta BB, PintoNeto AM, Costa-Paiva L. Low bone mass in human immunodeficiency virus-infected climacteric women receiving antiretroviral therapy: prevalence and associated factors. Menopause. 2014;22(2): 224-230.

121. Aberg JA, Gallant JE, Ghanem KG, Emmanuel P, Zingman BS, Horberg M; Infectious Diseases Society of America. Primary care guidelines for the management of persons infected with HIV: 2013 update by the HIV Medicine Association of the Infectious Diseases Society of America. Clin Infect Dis. 2014;58(1):1-10.

122. Hoy J. Bone disease in HIV: recommendations for screening and management in the older patient. Drugs Aging. 2015;32(7):549-558.

123. Papaioannou A, Morin S, Cheung A, et al. 2010 clinical practice guidelines for the diagnosis and management of osteoporosis in Canada: summary. CMAJ. 2010;182(17):1864-1873.

124. World Health Organization. WHO Scientific Group on the assessment of osteoporosis as the primary care level. Geneva, Switzerland: World Health Organization; 2004. Available from: http://www.who.int/chp/ topics/Osteoporosis.pdf. Accessed November 16, 2015.
125. World Health Organization. Adherence to long-term therapies: evidence for action. Geneva, Switzerland: World Health Organization; 2003. Available from: http://apps.who.int/iris/bitstream/10665/42682/1/92 41545992.pdf. Accessed November 16, 2015.

126. National Institutes of Health. Osteoporosis prevention, diagnosis and therapy. NIH Consensus Statement. 2000;17:1-45.

127. Cotter AG, Sabin CA, Simelane S, et al. Relative contribution of HIV infection, demographics and body mass index to bone mineral density. AIDS. 2014;28(14):2051-2060.

128. Dolan SE, Kanter JR, Grinspoon S. Longitudinal analysis of bone density in human immunodeficiency virus-infected women. J Clin Endocrinol Metab. 2006;91(8):2938-2945.

129. Brown TT, Qaqish RB. Antiretroviral therapy and the prevalence of osteopenia and osteoporosis: a meta-analytic review. AIDS. 2006; 20(17):2165-2174.

130. Walker Harris V, Brown TT. Bone loss in HIV-infected patients: evidence, clinical implications, and treatment strategies. J Infect Dis. 2012;205 Suppl 3:S391-S398

131. Brown TT, Hoy J, Borderi M, et al. Recommendations for evaluation and management of bone disease in HIV. Clin Infect Dis. 2015;60(8): $1242-1251$.

132. Yin MT, McMahon DJ, Ferris DC, et al. Low bone mass and high bone turnover in postmenopausal human immunodeficiency virus-infected women. J Clin Endocrinol Metab. 2010;95(2):620-629.

133. Arnsten JH, Freeman R, Howard AA, Floris-Moore M, Santoro N, Schoenbaum EE. HIV infection and bone mineral density in middleaged women. Clin Infect Dis. 2006;42(7):1014-1020.

134. McComsey GA, Tebas P, Shane E, et al. Bone disease in HIV infection: a practical review and recommendations for HIV care providers. Clin Infect Dis. 2010;51(8):937-946.

135. Cortes YI, Yin MT, Reame NK. Bone density and fractures in HIVinfected postmenopausal women: a systematic review. J Assoc Nurses AIDS Care. 2015;26(4):387-398.

136. Bonjoch A, Figueras M, Estany C, et al. High prevalence of and progression to low bone mineral density in HIV-infected patients: a longitudinal cohort study. AIDS. 2010;24(18):2827-2833.

137. McComsey GA, Kitch D, Daar ES, et al. Bone mineral density and fractures in antiretroviral-naïve persons randomized to receive abacavirlamivudine or tenofovir-disoproxil-fumarate-emtricitabine along with efavirenz or atazanvir-ritonavir: AIDS Clinical Trials Group A5224s, a substudy of ACTG A5202. J Infect Dis. 2011;203(12):1791-1801.

138. Bolland MJ, Wang TK, Grey A, Gamble GD, Reid IR. Stable bone density in HAART-treated individuals with HIV: a meta-analysis. J Clin Endocrinol Metab. 2011;96(9):2721-2731.

139. Brown TT, McComsey GA, King MS, Qaqish RB, Bernstein BM, da Silva BA. Loss of bone mineral density after antiretroviral therapy initiation, independent of antiretroviral regimen. $J$ Acquir Immune Defic Syndr. 2009;51(5):554-561.

140. Yin MT, Modarresi R, Shane E, et al. Effects of HIV infection and antiretroviral therapy with ritonavir on induction of osteoclast-like cells in postmenopausal women. Osteoporos Int. 2011;22(5):1459-1468.

141. Pinto-Neto LF, Ragi-Eis S, Vieira NF, et al. Low bone mass prevalence, therapy type, and clinical risk factors in an HIV-infected Brazilian population. J Clin Densitom. 2011;14(4):434-439.

142. Arnsten JH, Freeman R, Howard AA, Floris-Moore M, Lo Y, Klein RS. Decreased bone mineral density in aging men with or at risk for HIV infection. AIDS. 2007;21(5):617-623.

143. Stein EM, Yin MT, McMahon DJ, et al. Vitamin D deficiency in HIVinfected postmenopausal Hispanic and African-American women. Osteporos Int. 2011;22(2):477-487.

144. Yin MT, Dobkin J, Brudney K, et al. Bone mass and mineral metabolism in HIV+ postmenopausal women. Osteoporos Int. 2005;16(11): 1345-1352.

145. Sharma A, Cohen HW, Freeman R, Santoro N, Schoenbaum EE. Prospective evaluation of bone mineral density among middle-aged HIV-infected and unifected women: association between methadone use and bone loss. Maturitas. 2011;70(3):295-301. 
146. Prior J, Burdge D, Maan E, et al. Fragility fractures and bone mineral density in HIV-positive women: a case-control population-based study. Osteporos Int. 2007;18(10):1345-1353.

147. Dravid A, Kulkarni M, Borkar A, Dhande S. Prevalence of low bone mineral density among HIV patients on long-term suppressive antiretroviral therapy in resource-limited setting of western India. J Int AIDS Soc. 2014;17(4 Suppl 3):19567.

148. Sharma A, Flom PL, Rosen CJ, Schoenbaum EE. Racial differences in bone loss and relation to menopause among HIV-infected and uninfected women. Bone. 2015;77:24-30.

149. Yin MT, Shi Q, Hoover DR, et al. Fracture incidence in HIV-infected women: results from the Women's Interagency HIV Study. AIDS. 2010; 24(17):2679-2686.

150. Rodriguez M, Daniels B, Gunawardene S, Robbins GK. High frequency of vitamin D deficiency in ambulatory HIV-positive patients. AIDS Res Hum Retroviruses. 2009;25(1):9-14.

151. Dobs AS, Dempsey MA, Ladenson PW, Polk BF. Endocrine disorders in men infected with human immunodeficiency virus. Am J Med 1988;84(3 Pt 2):611-616.

152. Haug CJ, Aukrust P, Haug E, Morkrid L, Muller F, Froland SS. Severe deficiency of 1,25-dihdyroxyvitamin D3 in human immunodeficiency virus infection: association with immunological hyperactivity and only minor changes in calcium homeostasis. J Clin Endocrinol Metab. 1998; 83(11):3832-3838.

153. Huang JS, Wilkie SJ, Sullivan MP, Grinspoon S. Reduced bone density in androgen-deficient women with acquired immune deficiency syndrome wasting. J Clin Endocrinol Metab. 2001;86(8): 3533-3539.

154. Bolland MJ, Grey AB, Gamble GD, Reid IR. Low body weight mediates the relationship between HIV infection and low bone mineral density: a meta-analysis. J Clin Endocrinol Metab. 2007;92(12): 4522-4528.

155. Anastos K, Lu D, Shi O, et al. The association of bone mineral density with HIV infection and antiretroviral treatment in women. Antivir Ther. 2007;12(7):1049-1058.

156. Caputo BV, Traversa-Caputo GC, Costa C, Giovani EM. Evaluation of bone alterations in the jaws of HIV-infected menopausal women. Braz Oral Res. 2013;27(3):231-237.

157. Yin MT, Shu A, Zhang CA, et al. Trabecular and cortical microarchitecture in postmenopausal HIV-infected women. Calcif Tissue Int. 2013; 92(6):557-565.

158. Shiau S, Broun EC, Arpadi SM, Yin MT. Incident fractures in HIVinfected individuals: a systematic review and meta-analysis. AIDS. 2013;27(12):1949-1957.

159. Womack JA, Goulet JL, Gibert C, et al. Increased risk of fragility fractures among HIV infected compared to uninfected male veterans. PLoS One. 2011;6(2):e17217.

160. Triant VA, Brown TT, Lee H, Grinspoon SK. Fracture prevalence among human immunodeficiency virus (HIV)-infected versus nonHIV-infected patients in a large U.S. healthcare system. J Clin Endocrinol Metab. 2008;93(9):3499-3504.

161. Dao C, Young B, Buchacz K, et al. Higher and increasing rates of fracture among HIV-infected persons in the HIV-Outpatient Study (HOPS) compared to the general US population, 1994 to 2008 [abstract 128]. In: Program and abstracts of the 17th Conference on Retroviruses and Opportunistic Infections; February 18, 2010; San Francisco, California

162. Collin F, Duval X, Le Moing V, et al. Ten-year incidence and risk factors of bone fractures in a cohort of treated HIV-1 infected adults. AIDS. 2009;23(8):1021-1024.

163. Guerri-Fernandez R, Vestergaard P, Carbonell C, et al. HIV infection is strongly associated with hip fracture risk, independent of age, gender, and comorbidities: a population-based cohort study. J Bone Miner Res. 2013;28(6):1259-1263.

164. Grant PM, Kitch D, McComsey GA, et al. Low baseline CD4+ count is associated with greater bone mineral density loss after antiretroviral therapy initiation. Clin Infect Dis. 2013;57(10):1483-1488.
165. Carr A, Grund B, Neuhaus J, et al. Prevalence of and risk factors for low bone mineral density in untreated HIV infection: a substudy of the INSIGHT Strategic Timing of Antiretroviral Treatment (START) trial. HIV Med. 2015;16 Suppl 1:137-146.

166. Cassetti I, Madruga JV, Suleiman JM, et al. The safety and efficacy of tenofovir DF in combination with lamivudine and efavirenz through 6 years in antiretroviral-naïve HIV-1 infected patients. HIV Clin Trials. 2007;8(3):164-172.

167. Duvivier C, Kolta S, Assoumou L, et al. Greater decrease in bone mineral density with protease inhibitor regimens compared with nonnucleoside reverse transcriptase inhibitor regimens in HIV-1-infected naïve patients. AIDS. 2009;23(7):817-824.

168. Gallant JE, Staszewski S, Pozniak AL, et al. Efficacy and safety of tenofovir DF vs. stavudine in combination therapy in antiretroviralnaïve patients: a 3 year randomized trial. JAMA. 2004;292(2): 191-201.

169. Pan G, Wu X, McKenna MA, Feng X, Nagy TR, McDonald JM. AZT enhances osteoclastogenesis and bone loss. AIDS Res Hum Retroviruses. 2004;20(6):608-620.

170. Fux CA, Rauch A, Simcock M, et al. Tenofovir use is associated with an increase in serum alkaline phosphatase in the Swiss HIV Cohort Study. Antivir Ther. 2008;13(8):1077-1082.

171. Stellbrink HJ, Orkin C, Arribas JR, et al. Comparison of changes in bone density and turnover with abacavir-lamivudine versus tenofovir-emtricitabine in HIV-infected adults: 48-week results from the ASSERT study. Clin Infect Dis. 2010;51(8):963-972.

172. Mallon PW. HIV and bone mineral density. Curr Opin Infect Dis. 2010;23(1):1-8.

173. Tsekes G, Chrysos G, Douskas G, et al. Body composition changes in protease inhibitor-naïve HIV-infected patients treated with two nucleoside reverse transcriptase inhibitors. HIV Med. 2002;3(2):85-90.

174. Tebas P, Powderly WB, Claxton S, et al. Accelerated bone mineral loss in HIV-infected patients receiving potent antiretroviral therapy. AIDS. 2000;14(4):F63-F67.

175. Fernandez-Rivera J, Garcia R, Lozano F, et al. Relationship between low bone mineral density and highly active antiretroviral therapy including protease inhibitors in HIV-infected patients. HIV Clin Trials. 2003;4(5):337-346.

176. Mondy K, Yarasheski K, Powderly WG, et al. Longitudinal evolution of bone mineral density and bone markers in human immunodeficiency virus-infected individuals. Clin Infect Dis. 2003;36(4):482-490.

177. Jones S, Restrepo D, Kasowitz A, et al. Risk factors for decreased bone density and effects of HIV on bone in the elderly. Osteporos Int. 2008;19(7):913-918.

178. Bloch M, Tong WW, Hoy J, et al. Switch from tenofovir to raltegravir increases low bone mineral density and decreases markers of bone turnover 48 weeks. HIV Med. 2014;15(6):373-380.

179. Cotter AG, Mallon PW. The effects of untreated and treated HIV infection on bone disease. Curr Opin HIV AIDS. 2014;9(1):17-26.

180. Asboe D, Aitken C, Boffito, et al. British HIV Association guidelines for the routine investigation and monitoring of adult HIV-1-infected individuals, 2011. HIV Med. 2012;13(1):1-44.

181. European AIDS Clinical Society. EACS Guidelines Version 7.1. EACS; 2014. Available from: http://www.eacsociety.org/files/guidelines-7.1english.pdf. Accessed November 16, 2015.

182. World Health Organization Collaborating Centre for Metabolic Bone Diseases, University of Sheffield, UK. FRAX - WHO Fracture Risk Assessment Tool. Available from: https://www.shef.ac.uk/FRAX/ tool.jsp. Accessed November 16, 2015.

183. Watts NB, Bilezikian JP, Camacho PM, et al. American Association of Clinical Endocrinologists medical guidelines for clinical practice for the diagnosis and treatment of postmenopausal osteoporosis. Endocrine Practice. 2010;16 Suppl 3:1-36.

184. Allavena C, Delpierre C, Cuzin L, et al. High frequency of vitamin D deficiency in HIV-infected patients: effects of HIV-related factors and antiretroviral drugs. J Antimicrob Chemother. 2012;67(9): $2222-2230$. 
185. Mondy K, Powderly WG, Claxton SA, et al. Alendronate, vitamin D, and calcium for the treatment of osteopenia/osteoporosis associated with HIV infection. J Acquir Immune Defic Syndr. 2005;38(4): 426-431.

186. Rozenberg S, Lanoy E, Bentata M, et al. Effect of alendronate on HIV-associated osteoporosis: a randomized, double-blind, placebocontrolled, 96-week trial (ANRS 120). AIDS Res Hum Retroviruses. 2012;28(9):972-980.

187. Guaraldi G, Orlando G, Madeddu G, et al. Alendronate reduces bone resorption in HIV-associated osteopenia/osteoporosis. HIV Clin Trials. 2004;5(5):269-277.
188. McComsey GA, Kendall MA, Tebas P, et al. Alendronate with calcium and vitamin D supplementation is safe and effective for the treatment of decreased bone mineral density in HIV. AIDS. 2007;21(18): 2473-2482.

189. Bolland MJ, Grey AB, Horne AM, et al. Annual zoledronate increases bone density in highly active antiretroviral therapy-treated human immunodeficiency virus-infected men: a randomized controlled trial. J Clin Endocrinol Metab. 2007;92(4):1283-1288.

190. Huang J, Meixner L, Fernandez S, McCutchan JA. A double-blind, randomized controlled trial of zoledronate therapy for HIV-associated osteopenia and osteoporosis. AIDS. 2009;23(1):51-57.

\section{Publish your work in this journal}

The International Journal of Women's Health is an international, peerreviewed open-access journal publishing original research, reports, editorials, reviews and commentaries on all aspects of women's healthcare including gynecology, obstetrics, and breast cancer. The manuscript management system is completely online and includes a very quick and fair peer-review system, which is all easy to use. Visit http://www.dovepress.com/testimonials.php to read real quotes from published authors.

Submit your manuscript here: http://www.dovepress.com/international-journal-of-womens-health-journal 